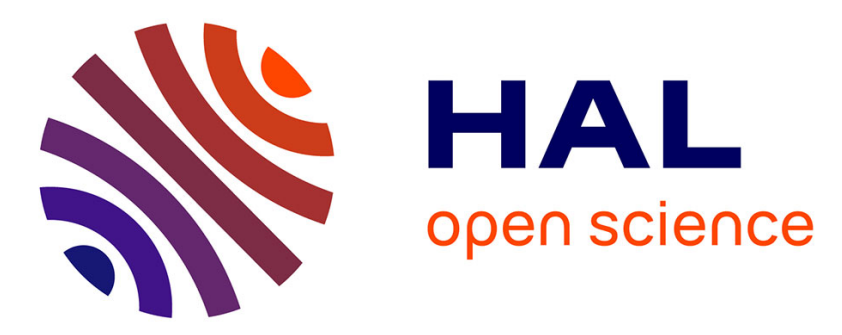

\title{
Numerical analysis of the Ti6Al4V behavior based on the definition of a new phenomenological model
}

\author{
Mariem Yaich, Yessine Ayed, Guénaël Germain, Zoubeir Bouaziz
}

\section{To cite this version:}

Mariem Yaich, Yessine Ayed, Guénaël Germain, Zoubeir Bouaziz. Numerical analysis of the Ti6Al4V behavior based on the definition of a new phenomenological model. International Journal of Advanced Manufacturing Technology, 2021, 116 (11-12), pp.3933-3951. 10.1007/s00170-021-07753-5 . hal03476637

\section{HAL Id: hal-03476637 \\ https://hal.science/hal-03476637}

Submitted on 13 Dec 2021

HAL is a multi-disciplinary open access archive for the deposit and dissemination of scientific research documents, whether they are published or not. The documents may come from teaching and research institutions in France or abroad, or from public or private research centers.
L'archive ouverte pluridisciplinaire HAL, est destinée au dépôt et à la diffusion de documents scientifiques de niveau recherche, publiés ou non, émanant des établissements d'enseignement et de recherche français ou étrangers, des laboratoires publics ou privés. 


\title{
Numerical analysis of the Ti6AI4V behavior based on the definition of a new phenomenological model
}

\author{
Mariem Yaich $^{1,2} \cdot$ Yessine Ayed $^{1} \cdot$ Guénaël Germain $^{1} \cdot$ Zoubeir Bouaziz $^{2}$
}

\begin{abstract}
The finite element modeling is significantly dependent on the accurate prediction of the material behavior. In order to increase the accuracy of numerical simulations, a new phenomenological model is proposed in this study. Its mathematical formulation allows suitable predictions of the Ti6Al4V sensitivity to strain rates and temperatures, while maintaining a low identification cost of its constitutive coefficients. A subroutine VUMAT is developed, and its reliability is investigated in the case of the modeling of uniaxial tensile and impact tests. In addition, the 3D numerical analysis of the machining process is investigated based on the definition of the rheological Johnson-Cook model and the proposed one. Experimental orthogonal machining tests are also established for several cutting conditions. The significant sensitivity of the chip serration, the segments geometry, and the cutting forces to the feed rate is pointed out. Comparisons of the numerical results corresponding to different constitutive models are carried out. High-correlation levels with the experimental results are reached with the definition of the proposed phenomenological model, which is not the case of the Johnson-Cook empirical law. Moreover, intuitive insights about the effect of cutting conditions on the material flow towards the workpiece edges are provided with the 3D modeling. A pronounced increase of the width of side burrs with the feed rate rise was underlined. The results presented in this study point out the inability of 2D numerical simulations to accurately predict the phenomena induced during the machining process, even in the case of an orthogonal machining.
\end{abstract}

Keywords Ti6Al4V $\cdot$ VUMAT $\cdot$ Constitutive model $\cdot$ Chip segmentation · Orthogonal machining

\section{Introduction}

The commonly used biphasic Ti6Al4V titanium alloy is known for its interesting strength-to-weight ratio, as well as its excellent resistance to corrosion. However, its low thermal conductivity and its significant mechanical properties, even for high temperatures, heavily influence its machinability [1]. The high gradients of plastic strains, strain rates, and temperatures, which are encountered during the Ti6Al4V machining, result in an accelerated tool wear, mainly in the case of high chemical affinity with the cutting tool material [2]. In

Mariem Yaich

yaichmariem@gmail.com

1 Arts et Métiers ParisTech, LAMPA, 2 bd du Ronceray, 49035 Angers, CEDEX, France

2 Laboratoire de Mécanique des Fluides Appliquées, Génie des Procédés et Environnement, Ecole Nationale d'Ingénieurs de Sfax, Université de Sfax, LR11ES57, 3, 038 Sfax, Tunisia order to understand the physical phenomena induced during the machining process, several experimental investigations have been performed in the literature review [3-5]. Different experimental devices (e.g., scanning electron microscope and high-frame rate camera.) have been used to enable access to local and instantaneous information, during the chip formation. In the experimental study of Pottier et al. [4], a new method based on the sub-millimeter procedure and the numerical post-processing has been proposed to determine the strain field in the segmented chip. However, many difficulties in terms of the experimental determination of the crack propagation within the chip have been faced. Despite the serious efforts to increase the reliability of experimental in situ and postmortem equipment, they are still insufficient for the study of the local and instantaneous phenomena induced in the cutting zones during the chip formation. Therefore, numerical simulations of the machining processes have been required, in addition to experimental tests [6].

The availability of powerful and efficient commercial codes has encouraged the establishment of numerical analyses, mainly in the case of the machining process, where severe 
dynamic and non-linear conditions are taking place. Their ability to reduce both time and cost, while providing key information for a better understanding of the machining process, has encouraged their widespread adoption in the last decades. Several numerical studies of the machining process have been set up in the literature [7-13]. They have been focused on the prediction of the chip segmentation, the cutting forces, the tribology, the surface integrity, the tool edge preparation, etc. However, the reliability of the finite elements (FE) modeling is deeply dependent on the adequate definition of numerical parameters and the workpiece material behavior. During the machining process, the workpiece is subjected to severe nonlinearities. Therefore, an adequate prediction of the material behavior, under wide ranges of plastic strain, strain rate, and temperature, is required. The literature review has pointed out the definition of several constitutive models, which are classified in three categories: the empirical, the semi-empirical, and the physically based models [14-16]. These latter are based on the definition of internal variables, which allow taking into account the history of the material deformation, the physical phenomena, and the changes followed by the microstructure of the machined material (e.g., the dislocations' density, its orientation, and the grain size) [17]. Despite the reliability of these constitutive models, they have been uncommonly used for the modeling of the machining process, in which heavy interactions between the involved phenomena are taking place. In addition, these constitutive models are characterized by the complicated identification of their numerous and coupled coefficients, where the setting up of particular experimental tests and the use of evolved equipment are deeply required. Moreover, the numerical implementation of these physically based models in the commercial codes remains a genuine task. On the other hand, the semi-empirical models, with a less complex mathematical formulation, present an interesting alternative. These models are advantageous since they allow a well prediction of the material behavior. However, problems related to the identification and the implementation of the semi empirical models in the commercial codes are raised. This explains its uncommon use for the modeling of forming processes, totally unlike the empirical models [17]. The thermo-visco-plastic Johnson-Cook (JC) model [18] has been widely used for the numerical analysis of the machining process [8, 19-22]. Its outstanding success is due to its ability to take into account the effects of plastic strains, strain rates, and temperatures. It is also attributed to its implementation in many commercial codes. In addition, only few experimental tests are required for its identification due to its uncoupled terms and the low number of its constitutive parameters. However, the accuracy of this empirical model is generally limited for particular loading conditions. In addition, the divergence of numerical simulations related to the definition of low strain rates is problematic [23]. A discontinuous regularization has been widely adopted to overcome this problem. It consists in neglecting the viscosity effect, for strain rates below the reference one (case of the commercial code Abaqus $\left.{ }^{\circledR}\right)$. Ayed et al. [24] have also underlined the inability of the JC rheological model to suitably fit the experimental flow stress-plastic strain curves for several ranges of plastic strain rates and temperatures. The authors have attributed this inadequacy to the JC parameters $C$ and $m$. In addition, Laakso and Niemi [25] have noted errors up to $42 \%$ between the experimental flow stresses and those computed based on the JC empirical law. Its definition for the modeling of the machining process has led to heavily overestimated forces and chip thicknesses, for the investigated cutting conditions. Liu et al. [26] have also underlined its inability to reliably predict the thermal softening effects in the dual-phase steel plate DP600, for temperatures ranged between 300 and $1200 \mathrm{~K}$.

Therefore, this study aims to improve the reliability of the FE modeling of the Ti6Al4V machining process. It focuses on increasing the correlation between experimental and numerical results. A new phenomenological model based on the investigation of Ayed et al. [24] is proposed. An exponential viscosity term and a modified JC thermal softening law are used to reproduce the Ti6Al4V behavior under several strain rates and temperatures, respectively. Attention is paid to the effect of this constitutive model on the accurate prediction of the material behavior, to the identification of its coefficients, as well as to its implementation in the numerical software Abaqus ${ }^{\circledR}$. The identification of its coefficients is performed based on the non-linear regression method. The experimental compression tests of Braham-Bouchnak [27] are used. Comparisons between the experimental flow stress-plastic strain curves and the computed ones are carried out. The advantageous of proposed modifications are discussed. The validation of the new phenomenological model is performed, for several loading conditions. A user-material subroutine VUMAT is developed for its implementation in the Abaqus ${ }^{\circledR} /$ Explicit software. Numerical simulations of uniaxial tensile tests and extremely dynamic impact tests are set up. Experimental and numerical studies of the orthogonal Ti6Al4V machining are carried out, for different cutting conditions. Comparisons between the simulated chips and forces, and the experimental ones are set up. The efficiency of the proposed rheological model, in terms of accurately predicting the chip segmentation, its geometry, and the tangential and feed forces, is studied. Attention is also paid to the material flow towards the workpiece sides. The 3D modeling of the orthogonal machining highlighted the sensitivity of side burrs to the cutting conditions.

\section{Material rheological models}

Three constitutive laws were used in this study for the prediction of the Ti6Al4V alloy behavior: the thermo-visco-plastic JC model [18], the empirical model of Ayed et al. [24] 
(MJC1), and that proposed in this study (MJC2). The general mathematical formulation of all investigated models is given by Eq. (1). The material flow stress is expressed through three uncoupled terms: the Ludwik plastic hardening term $H\left(\varepsilon_{p}\right)$ [28] (given by Eq. (2)), the strain rate sensitivity term $G(\dot{\varepsilon})$, and the thermal softening term $F(T)$. For both JC and MJC1 models, a logarithmic function was used to predict the effect of the strain rate (see Eqs. (3) and (4) respectively). A function $C(\vec{\varepsilon})$, which depends on the strain rate, was defined in the MJC1 model instead of the JC coefficient $C$ (see Eq. (5)). Contrariwise, an exponential viscosity term was used in the MJC2 model to predict the Ti6Al4V sensitivity to the strain rate (see Eq. (6)). Nonetheless, a function $m(T)$ was defined to the thermal softening terms of both MJC1 and MJC2 models instead of the JC coefficient $m$ (as shown by Eq. (8)). The $m(T)$ expression is given by Eq. (9). It aimed to overcome the limitations of the JC thermal softening law given by Eq. (7), thus enabling accurate predictions of the Ti6Al4V behavior under wide ranges of temperatures.

$\sigma=H\left(\varepsilon_{p}\right) \times G(\dot{\varepsilon}) \times F(T)$

where, $\varepsilon_{p}, \dot{\varepsilon}$, and $T$ are the equivalent plastic strains, the strain rate, and the temperature, respectively. $H\left(\varepsilon_{p}\right), G(\dot{\varepsilon})$, and $F(T)$ are the hardening, viscosity, and thermal softening terms, respectively.

$H(\varepsilon)=A+B \times \varepsilon_{p}^{n}$

where, $A, B$, and $n$ are the initial material yield stress at room temperature, the Ludwik hardening modulus, and the Ludwik hardening exponent, respectively.

$G_{\mathrm{JC}}(\dot{\varepsilon})= \begin{cases}1 & \left(\text { For : } \dot{\varepsilon} \leq \dot{\varepsilon}_{0}\right) \\ 1+C \times \ln \left(\frac{\dot{\varepsilon}}{\dot{\varepsilon}_{0}}\right) & \left(\text { For }: \dot{\varepsilon}>\dot{\varepsilon}_{0}\right)\end{cases}$

where $C$ is the JC strain rate sensitivity coefficient. $\dot{\varepsilon}_{0}$ is the reference equivalent plastic strain rate corresponding to the transition from static loadings to dynamic ones.

$G_{\mathrm{MJC} 1}(\dot{\varepsilon})= \begin{cases}1 & \left(\text { For }: \dot{\varepsilon} \leq \dot{\varepsilon}_{0}\right) \\ 1+C(\dot{\varepsilon}) \times \ln \left(\frac{\dot{\varepsilon}}{\dot{\varepsilon}_{0}}\right) & \left(\text { For }: \dot{\varepsilon}>\dot{\varepsilon}_{0}\right)\end{cases}$

where $C(\overline{\dot{\varepsilon}})$ is the viscosity function and it is computed as follows:

$\left.C(\overline{\dot{\varepsilon}})=C_{1} \times \exp \quad C_{2} \times \ln \left(\frac{\overline{\dot{\varepsilon}}}{\dot{\varepsilon_{0}}}\right)\right)$ where $C_{1}$ and $C_{2}$ are the strain rate sensitivity coefficients.

$G_{\mathrm{MJC} 2}(\dot{\varepsilon})=Y_{0}+A_{0} \times \exp \left(\frac{R_{0} \overline{\dot{\varepsilon}}}{\dot{\varepsilon}_{0}}\right)$

where $Y_{0}, A_{0}$, and $R_{0}$ are the strain rate sensitivity coefficients of the proposed model.

$F_{\mathrm{JC}}(T)= \begin{cases}1 & \left(\text { For }: T<T_{\text {room }}\right) \\ 1-\left(\frac{T-T_{\text {room }}}{T_{\text {melt }}-T_{\text {room }}}\right)^{m} & \left(\text { For }: T_{\text {room }} \leq T \leq T_{\text {melt }}\right) \\ 0 & \left(\text { For }: T>T_{\text {melt }}\right)\end{cases}$

where $m$ is the JC thermal softening coefficient. $T_{\text {room }}$ and $T_{\text {melt }}$ are the room temperature and the melting one, respectively. They are equal to $293 \mathrm{~K}$ and $1943 \mathrm{~K}$, respectively [27].

$$
F_{\text {JCM }(1,2)}(T)= \begin{cases}1 & \left(\text { For }: T<T_{\text {room }}\right) \\ 1-\left(\frac{T-T_{\text {room }}}{T_{\text {melt }}-T_{\text {room }}}\right)^{m(T)} & \left(\text { For }: T_{\text {room }} \leq T \leq T_{\text {melt }}\right) \\ 0 & \left(\text { For }: T>T_{\text {melt }}\right)\end{cases}
$$

where $m(T)$ is the thermal softening sensitivity exponent and it is written as follows:

$m(T)=m_{1} \times\left(1-\exp \left(m_{2}\left(T-T_{\beta}\right)\right)\right)$

where $T_{\beta}$ is the Ti6Al4V $\beta$-transus temperature and it is equal to $1253 \mathrm{~K}$ [27]. $m_{1}$ and $m_{2}$ are the thermal softening coefficients of the proposed model.

In this study, the same experimental compression tests of the literature [29] were used for the identification of all investigated rheological models (JC, MJC1, and MJC2 models). The compression tests of cylindrical specimens have been carried out at several reference speeds and initial temperatures (see Table 1). Graphite papers and a nickel paste were applied in the anvilspecimen interface in order to reduce the friction conditions, as well as to promote the thermal conductivity, mainly in the case of compression tests under high temperatures. The specimens were heated by an electric current (Joule effect), and thermocouples were used for the temperature determination.

The non-linear regression method was used for the identification of all studied rheological models. The optimal sets of constitutive coefficients $\left(P_{\mathrm{JC}}=\{A, B, n, C, m\}, P_{\mathrm{MJC} 1}=\{A, B\right.$, $\left.n, C_{1}, C_{2}, m_{1}, m_{2}\right\}$ and $\left.P_{\mathrm{MJC} 2}=\left\{A, B, n, Y_{0}, A_{0}, R_{0}, m_{1}, m_{2}\right\}\right)$ were determined, based on the reduction, in a least square sense, of the errors between the experimental flow stress-plastic strain curves and the computed ones for the same loading conditions. The general error function given by Eq. (10) was defined in this study. A specific iterative identification procedure was used for a better adjustment of the material coefficients, thus a reliable fitting of experimental curves. It consisted of three steps. First of 
Table 1 Experimental conditions of the compression tests of BrahamBouchnak [27]

\begin{tabular}{ll}
\hline Compression speed $V(\mathrm{~mm} / \mathrm{s})$ & Initial temperature $T_{0}(\mathrm{~K})$ \\
\hline 0.1 & 293 \\
& 473 \\
& 673 \\
& 873 \\
& 1073 \\
0.1 & 293 \\
1 & \\
10 & \\
100 & \\
1000 & \\
\hline
\end{tabular}

all, the isotropic hardening coefficients $(A, B$, and $n)$ were determined. Afterward, the material thermal softening parameters were computed. This choice was justified by the self-heating of the specimen material, which was induced during dynamic tests. The stress-plastic strain curves corresponding to the reference strain rate and several initial temperatures were used. Finally, the strain rate sensitivity coefficients were determined. Table 2 regroups the constitutive coefficients of all compared rheological models.

$Q=\sum_{i=1}^{n_{i}} \gamma_{i} \times\left[\left(\sigma_{c}\right)_{i}-\left(\sigma_{\exp }\right)_{i}\right]^{2}$

where $n_{i}$ is the total number of experimental measurements for all investigated loading conditions. $\gamma_{i}$ is the weighting factor and it is given by Eq. (11). $\sigma_{c}$ is the computed flow stress and $\sigma_{\exp }$ is the experimental one.

$\gamma_{i}=1 / \sum_{i=1}^{n_{i}}\left[\left(\sigma_{\exp }\right)_{i}\right]^{2}$

The adequacy of investigated rheological models in terms of accurately predicting the experimental Ti6Al4V behavior was investigated. Figure 1 illustrates the comparison of experimental flow stress-plastic strain curves to the computed ones based on the identified constitutive models, for different initial strain rates. The definition of the empirical JC model resulted in the most mismatched results, due to its parameter $C$. It led to a quasi-linear evolution of the $G$ function, as shown in Fig. 2. Therefore, high relative errors (about 17\%) were computed, while the mismatch between the experimental results and the computed ones was below $6.12 \%$ and $5.7 \%$ when the modified JC models (MJC1 and MJC2 models, respectively) were defined. For all compared rheological models, the most mismatched results were noted for $\overline{\dot{\varepsilon}}=100 \mathrm{~s}^{-1}$ (see Fig. 1). For lower strain rates, the definition of the $\mathrm{MJC} 1$ model resulted in a slight improvement of the JC empirical model predictions. However, flow stresses very close to the experimental ones were computed with the MJC2 model. Therefore, the proposed viscosity law allowed more accurate predictions of the strain rate effects on the Ti6Al4V alloy behavior. In addition, it enabled overcoming the divergence of the numerical simulations, when the JC and MJC1 models were used, due to the definition of the logarithmic function for $\overline{\dot{\varepsilon}}<\dot{\varepsilon}_{0}$.

Figure 3 illustrates significant errors between the experimental stress-plastic strain curves and those computed with the empirical JC model. This mismatched reproduction of the temperature effect on the Ti6Al4V titanium alloy was attributed to the JC coefficient $m$. Its value deeply decreased from 0.9 to 0.25 for temperatures ranged between 473 and $1073 \mathrm{~K}$, respectively, as illustrated by the black crosses of Fig. 4a. The definition of the same JC thermal softening coefficients for different temperatures resulted in an inadequate representation of the Ti6A14V behavior. However, high agreements between the computed and the experimental flow stresses were noted, when the modified thermal softening law given by Eq. (8) was used (see Fig. 3b). The definition of the $m(T)$ function allowed a suitable reproduction of the $m$ variation with the temprature (see Fig. 4). It enabled taking into account the effects of thermal softening on the flow stress, which decreased with the temperature rise as underlined by Laakso and Neimi [25].

These preliminary results pointed out the efficiency of the proposed rheological model in terms of allowing more reliable
Table 2 Constitutive coefficients of the $\mathrm{JC}, \mathrm{MJC} 1$, and $\mathrm{MJC} 2$ models

\begin{tabular}{|c|c|c|c|c|c|c|c|c|}
\hline \multirow{3}{*}{$\begin{array}{l}\text { Model } \\
\text { JC }\end{array}$} & \multicolumn{8}{|c|}{ Constitutive coefficients } \\
\hline & \multicolumn{3}{|c|}{ Hardening coefficients } & \multicolumn{3}{|c|}{ Viscosity coefficients } & \multicolumn{2}{|c|}{ Thermal softening coefficients } \\
\hline & $A(\mathrm{MPa})$ & $B(\mathrm{MPa})$ & $n$ & $C$ & & & $m$ & \\
\hline & 518.54 & 941.12 & 0.16 & 0.0087 & & & 0.58 & \\
\hline \multirow[t]{2}{*}{ MJC1 } & $A(\mathrm{MPa})$ & $B(\mathrm{MPa})$ & $n$ & $C_{1}$ & $C_{2}$ & & $m_{1}$ & $m_{2}$ \\
\hline & 518.54 & 941.12 & 0.16 & 0.0027 & 0.198 & & 1.628 & 0.001 \\
\hline \multirow[t]{2}{*}{ MJC2 } & $A(\mathrm{MPa})$ & $B(\mathrm{MPa})$ & $n$ & $Y_{0}$ & $A_{0}$ & $R_{0}$ & $m_{1}$ & $m_{2}$ \\
\hline & 518.54 & 941.12 & 0.16 & 1.115 & -0.124 & -0.007 & 1.628 & 0.001 \\
\hline
\end{tabular}



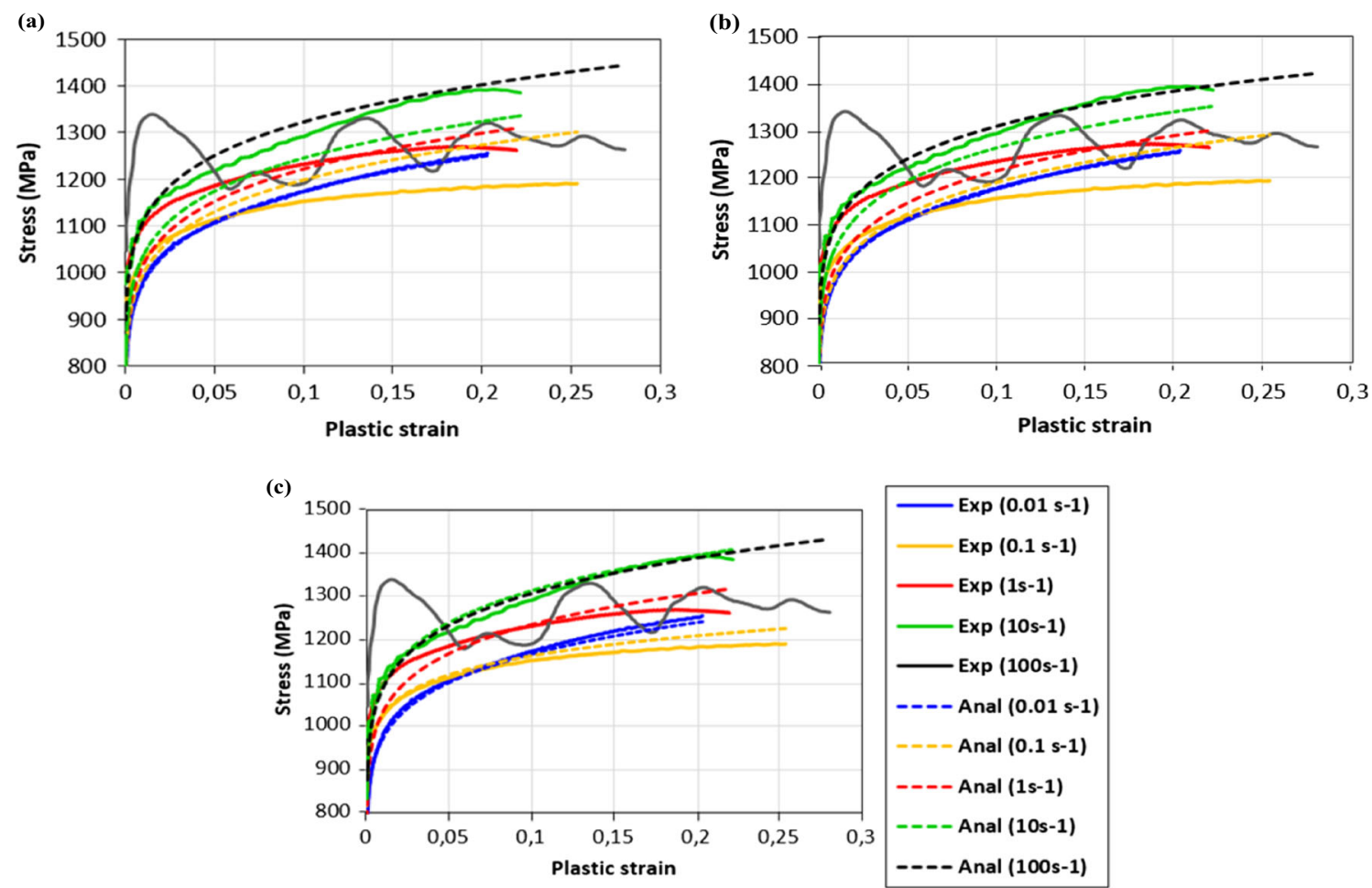

Fig. 1 Comparison of the experimental true stress-plastic strain curves to the computed ones for different strain rates $\left(T_{0}=293 \mathrm{~K}\right)$. a JC. b MJC1. $\mathbf{c}$ MJC2 models

predictions of the Ti6Al4V behavior for several strain rates and temperatures. The fact that the same JC hardening term was defined, this allowed reducing the identification cost. Only the determination of the strain rate of the viscosity and thermal softening terms was required.

\section{VUMAT definition and validation}

\subsection{VUMAT definition}

The implementation of the empirical JC model and the proposed one in the FE software Abaqus ${ }^{\circledR}$ was done. The explicit

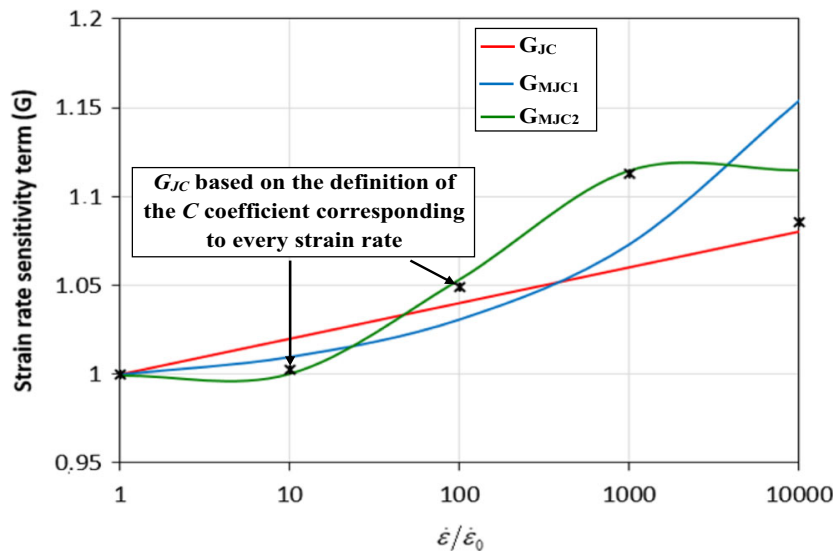

Fig. 2 Comparison of studied strain rate sensitivity terms scheme, which is suitable for dynamic and nonlinear conditions similar to those induced during the Ti6Al4V machining, was adopted. A user material subroutine VUMAT was developed, in which the investigated rheological and damage equations were integrated. The material parameters were defined in a vector form, and the order of its components was imperatively respected. The fact that severe dynamic phenomena are involved during the Ti6Al4V machining, hindering consequently the modeling convergence, sufficiently small increments were used. In this study, an assumption of isotropic material behavior was made the fact that no cyclic loadings, and thereby Bauschinger effects, were investigated. The von Mises plasticity criterion, which is commonly used for the modeling of the material hardening, was defined. A scalar yield function $f$ was computed (see Eq. (12)). The elastoplastic transition was verified at every time increments $\Delta t$. If $f<0$, an elastic (reversible) material deformation was assumed; and the von Mises equivalent stress increased from zero to the initial yield surface (see Fig. 5). However, a plastic deformation was taking place once $f \geq 0$. Hence, an increase of the yield surface was taking place. Therefore, a massive proliferation of dislocations (stacking defects) within the metal crystal was encountered [30, 31]. Significant irreversible motion of dislocations was taking place during the machining of the Ti6Al4V alloy according to Yang and Liu [32]. It led to severe changes of the material properties and a drift of the $\sigma_{(t+\Delta t)}$ stress (see Fig. 5). Indeed, a correction of the positive yield function was required. The general approach adopted to explicitly implement 
Fig. 3 Experimental and computed stress-plastic strain curves corresponding to different initial temperatures

$\left(\dot{\varepsilon}_{0}=0.01 \mathrm{~s}^{-1}\right)$. a JC and $\mathbf{b}$

MJC2 models

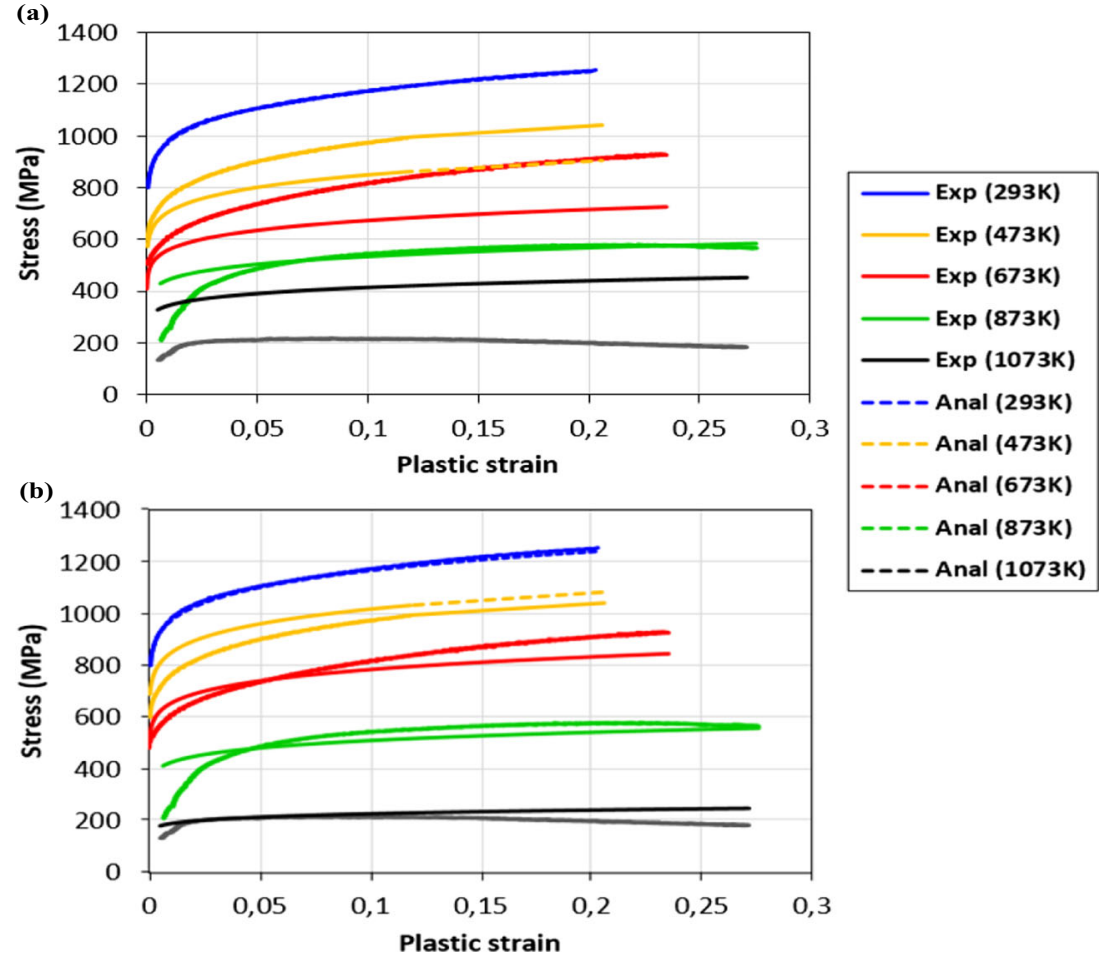

(a) the compared material models is illustrated in Fig. 6. It was based on the study of Bednarcyk et al. [33], in which the authors used the return mapping method to integrate the plasticity equations. A correction factor $m_{\text {corr }}$ given by Eq. (13)
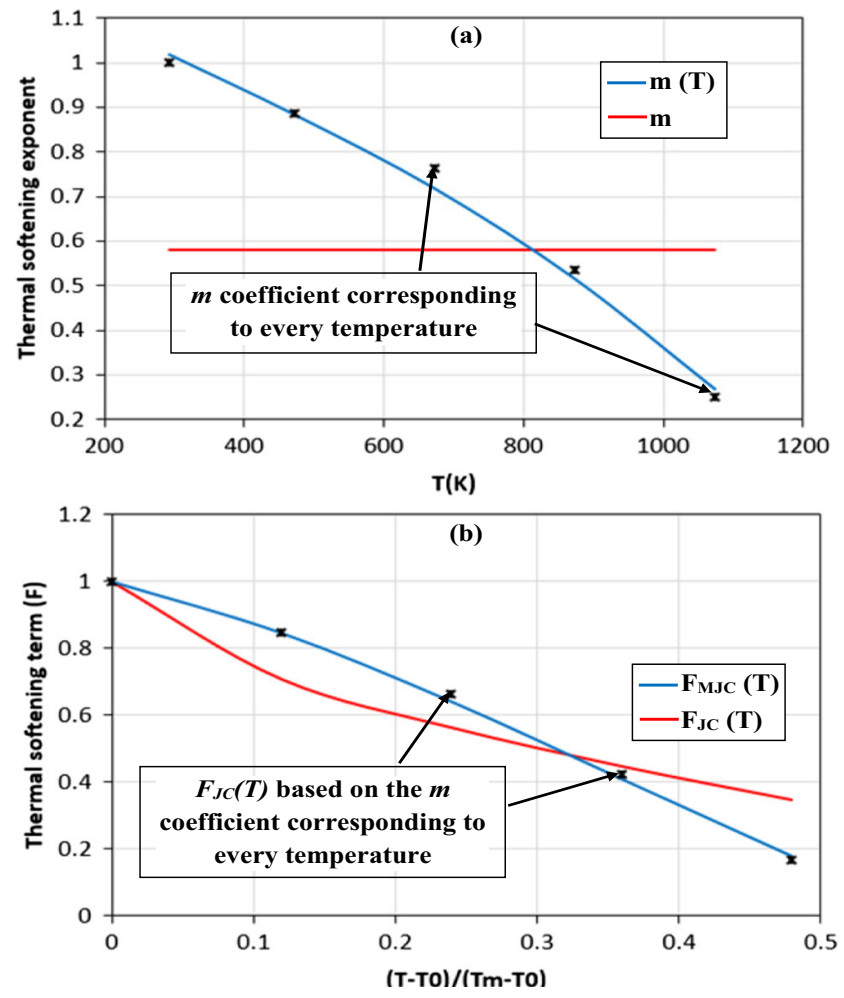

Fig. 4 Comparison of the thermal softening (a) exponents and ( $m$ and $m(T))(\mathbf{b})$ terms was defined in order to enable the radial return mapping of the integration scheme. It allowed bringing back the updated stress onto the yield area.

$f=\bar{\sigma}_{\mathrm{pr}}-\sigma_{y}(\bar{\varepsilon}, \overline{\dot{\varepsilon}}, T)$

where, $\bar{\sigma}_{p r}$ is the equivalent predictor stress. $\sigma_{y}(\bar{\varepsilon}, \overline{\dot{\varepsilon}}, T)$ is the yield stress. It was computed based on the JC rheological model and the proposed one, in this study.

$m_{\mathrm{corr}}=\frac{\left(\sigma_{y}(\bar{\varepsilon}, \overline{\dot{\varepsilon}}, T)\right)_{(t+\Delta t)}}{\left(\bar{\sigma}_{\mathrm{pr}}\right)_{(t+\Delta t)}}$

where $\left(\sigma_{y}(\bar{\varepsilon}, \bar{\varepsilon}, T)\right)_{(t+\Delta t)}$ and $\left(\bar{\sigma}_{\mathrm{pr}}\right)_{(t+\Delta t)}$ are the updated yield stress and the equivalent predictor stress, respectively.

Based on the numerical analysis of Pipard [34], the correction factor was only applied to the deviatoric stress. Therefore, the effective stress tensor $\left(\sigma_{\text {eff }}\right)_{(t+\Delta t)}$ was explicitly computed based on Eq. (14). This assumption was justified by the incompressible conditions of nonporous metals, which plastically deform without resulting in a volume change.

$\left[\sigma_{\mathrm{eff}}\right]_{(t+\Delta t)}=\left(\sigma^{h}\right)_{(t+\Delta t)} \times[I]+m_{\mathrm{corr}} \times\left[\sigma_{\mathrm{pr}}^{\mathrm{dev}}\right]_{(t+\Delta t)}$ 
Fig. 5 Schematic representation of $\mathbf{a}$ the yield areas in the plane stress and $\mathbf{b}$ the uniaxial stressstrain curves (case of an isotropic hardening plasticity)

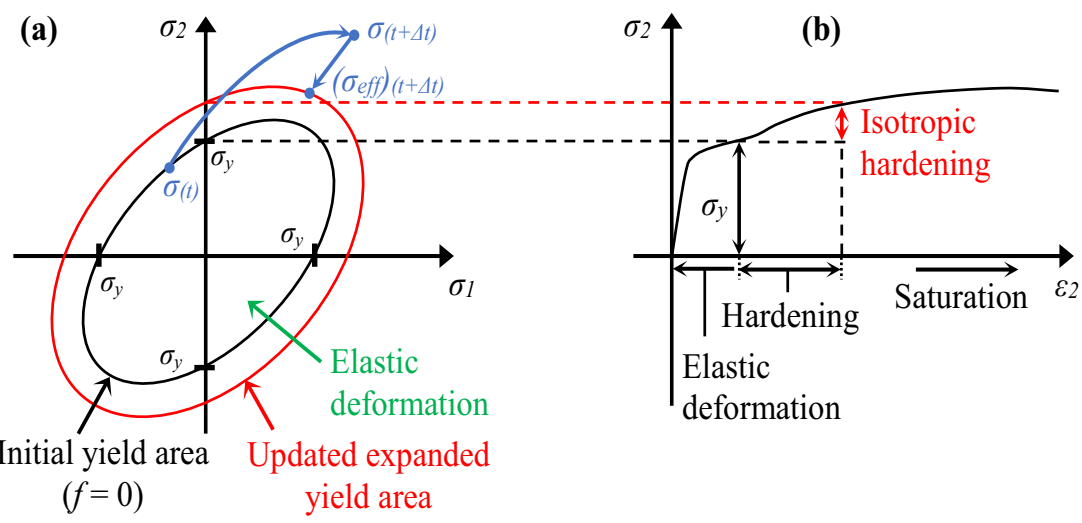

where $\left(\sigma^{h}\right)_{(t+\Delta t)}$ is the updated hydrostatic stress, $m_{\text {corr }}$ is the correction factor, and $\left[\sigma_{\mathrm{pr}}^{\mathrm{dev}}\right]_{(t+\Delta t)}$ is the updated deviatoric stress tensor.

The equivalent plastic strain increment $\left(\Delta \bar{\varepsilon}_{p}\right)_{(t+\Delta t)}$ was explicitly determined based on Eq. (15).

$$
\left(\Delta \varepsilon_{p}\right)_{(t+\Delta t)}=\sqrt{\frac{2}{3}\left[\Delta \varepsilon_{p}^{\operatorname{dev}}\right]_{(t+\Delta t)}:\left[\Delta \varepsilon_{p}^{\operatorname{dev}}\right]_{(t+\Delta t)}}
$$

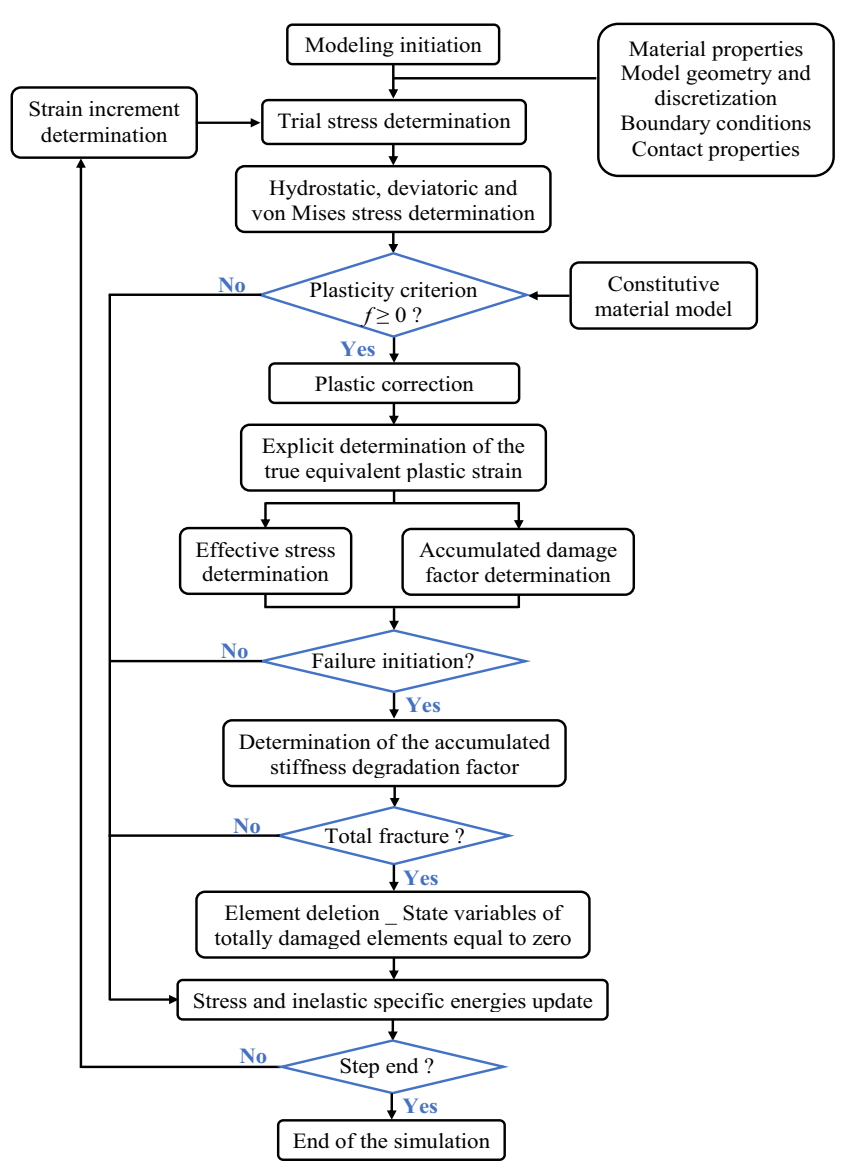

where $\left[\Delta \varepsilon_{p}^{\mathrm{dev}}\right]_{(t+\Delta t)}$ is the deviatoric plastic strain tensor (see Eq. (16)). It was used for the $\left(\Delta \bar{\varepsilon}_{p}\right)_{(t+\Delta t)}$ prediction (see Eq. (17)).

$$
\left[\Delta \varepsilon_{p}^{\mathrm{dev}}\right]_{(t+\Delta t)}=\left(\frac{1-m_{\mathrm{corr}}}{2 \times \mu_{\mathrm{Lame}}}\right) \times\left[\sigma_{\mathrm{pr}}^{\mathrm{dev}}\right]_{(t+\Delta t)}
$$

where $\mu_{\text {Lame }}$ is the Lame factor. $m_{\text {corr }}$ is the correction factor, which expression is given by Eq. (13). $\left[\sigma_{\mathrm{pr}}^{\mathrm{dev}}\right]_{(t+\Delta t)}$ is the updated deviatoric stress tensor.

$$
\left(\Delta \bar{\varepsilon}_{p}\right)_{(t+\Delta t)}=\left(\frac{1-m_{\text {corr }}}{3 \times \mu_{\text {Lame }}}\right) \times\left(\bar{\sigma}_{\text {pr }}\right)_{(t+\Delta t)}=\frac{\left(\bar{\sigma}_{\text {pr }}\right)_{(t+\Delta t)}-\left(\sigma_{y}(\bar{\varepsilon}, \bar{\varepsilon}, T)\right)_{(t+\Delta t)}}{3 \times \mu_{\text {Lame }}}
$$

where $\left(\bar{\sigma}_{\mathrm{pr}}\right)_{(t+\Delta t)}$ is the equivalent predictor stress. $\left(\sigma_{y}(\bar{\varepsilon}, \bar{\varepsilon}, T)\right)_{(t+\Delta t)}$ is updated yield stress and it is computed as follows:

$$
\left(\sigma_{y}(\bar{\varepsilon}, \bar{\varepsilon}, T)\right)_{(t+\Delta t)}=\left(\sigma_{y}(\bar{\varepsilon}, \bar{\varepsilon}, T)\right)_{(t)}+\left(\frac{d \sigma_{y}(\bar{\varepsilon}, \bar{\varepsilon}, T)}{d \bar{\varepsilon}}\right)_{(t)} \times\left(\Delta \bar{\varepsilon}_{p}\right)_{(t+\Delta t)}+\ldots
$$

As shown in Eq. (18), a linear hardening was considered, since an explicit integration scheme and extremely small time increments were considered. Therefore, Eq. (19) was used to determine the plastic strain increment.

$$
\begin{aligned}
& \left(\Delta \bar{\varepsilon}_{p}\right)_{(t+\Delta t)}=\frac{\left(\bar{\sigma}_{\mathrm{pr}}\right)_{(t+\Delta t)}-\left(\sigma_{y}(\bar{\varepsilon}, \bar{\varepsilon}, T)\right)_{(t)}}{3 \times \mu_{\text {Lame }}+\left(\frac{d \sigma_{y}(\bar{\varepsilon} \bar{\varepsilon}, T)}{d \bar{\varepsilon}}\right)_{(t)}} \\
& \text { where }\left(\frac{d \sigma_{y}(\bar{\varepsilon} \bar{\varepsilon}, T)}{d \bar{\varepsilon}}\right) \text { is the yield hardening parameter. }
\end{aligned}
$$

Fig. 6 Flowchart of the VUMAT 
During the machining process of the Ti6Al4V alloy, a segmented chip is usually formed, even under low cutting conditions. The modeling of the chip formation and segmentation requires taking into account the damage behavior of ductile materials, when the Lagrangian formulation is used. The definition of damage models allows the prediction of the failure initiation followed by the stiffness degradation until reaching the total fracture of the mesh. In this study, the JC damage model [35] was used to determine the damage onset. It represents a cumulative failure law, where the magnitude of the equivalent plastic strain within a deformed finite element is computed, and it is compared to that corresponding to the failure initiation $\varepsilon_{\mathrm{JCD}}$ (see Eq. (21)). The damage occurs in the finite element once the cumulative scalar damage parameter $w$ reaches unity (see Eq. (20)). It results in the flow stress degradation, which progressively decreases until reaching the total failure of the mesh. Equation (22) was used to predict the effect of damage evolution on the ductile material behavior, until the occurrence of the total fracture. Both linear and exponential forms of the damage evolution (given by Eqs. (23) and (24) respectively) were implemented in the VUMAT to model the progressive stiffness degradation. These failure criteria are based on the definition of the characteristic length $L$ of finite elements, which depends on the mesh topology (FE geometry, full/reduced integration, number of nodes per element). It allows taking into account the effects of mesh properties on the numerical simulations.

$\omega_{(t+\Delta t)}=\omega_{(t)}+\Delta \omega_{(t+\Delta t)}=\sum\left(\frac{\Delta \varepsilon_{p}}{\varepsilon_{\mathrm{JCD}}}\right)$

where $\varepsilon_{\mathrm{JCD}}$ is the plastic strain when the damage is initiated in a finite element. It is computed as follows:

$$
\begin{aligned}
\varepsilon_{\mathrm{JCD}}= & {\left[D_{1}+D_{2} \times \exp \left(D_{3} \frac{\sigma_{h}}{\sigma_{\mathrm{pr}}}\right)\right] } \\
& \times\left[1+D_{4} \times \ln \left(\frac{\dot{\varepsilon}}{\dot{\varepsilon_{0}}}\right)\right] \\
& \times\left[1+D_{5} \times\left(\frac{T-T_{0}}{T_{m}-T_{0}}\right)\right]
\end{aligned}
$$

where $D_{i(i=1,2,3,4 \text {, and 5) }}$ are the JC damage coefficients which values are regrouped in Table 3. $\sigma_{h}$ and $\sigma_{\mathrm{pr}}$ represent the hydrostatic and the predictor stresses, respectively. $\dot{\varepsilon}_{0}$ is

Table 3 JC damage coefficients [36]

\begin{tabular}{llllll}
\hline Damage coefficient & $D_{1}$ & $D_{2}$ & $D_{3}$ & $D_{4}$ & $D_{5}$ \\
\hline Value & -0.09 & 0.25 & -0.5 & 0.014 & 3.87 \\
\hline
\end{tabular}

the reference strain rate, $T_{m}$ is the melting temperature, and $T_{0}$ is the reference one.

$\left[\sigma_{\mathrm{eff}}\right]_{(t+\Delta t)}=\left(1-\left(D_{\mathrm{ev}}\right)_{(t+\Delta t)}\right) \times[\widetilde{\sigma}]_{(t+\Delta t)}$

where $[\widetilde{\sigma}]_{(t+\Delta t)}$ is the stress tensor when the damage effect is neglected. $\left(D_{\mathrm{ev}}\right)_{(t+\Delta t)}$ is the damage evolution parameter at $t+\Delta t$ (see Eqs. (23) and (24)). It reproduces the stiffness degradation within the damaged finite element until its total fracture. Its implementation aimed to avoid the problems of the numerical solution's dependency to the mesh, the fact that the damaged material behavior was no more given as a stressstrain response, but as a stress-displacement response.

$\begin{aligned}\left(D_{\mathrm{ev}}\right)_{(t+\Delta t)} & =\frac{\left(\Delta \bar{u}_{p}\right)_{(t+\Delta t)}}{\bar{u}_{f}}=\frac{L \times\left(\varepsilon_{p}\right)_{(t+\Delta t)}}{\bar{u}_{f}} \\ \left(D_{\mathrm{ev}}\right)_{(t+\Delta t)} & =1-\exp \left(--_{0}^{\bar{u}_{p}}\left(\frac{\sigma_{y_{0}}(\bar{\varepsilon}, \bar{\varepsilon}, T)}{G_{f}}\right) \times \mathrm{d} \bar{u}_{p}\right)\end{aligned}$

where $\bar{u}_{p}$ is the equivalent plastic displacement. $\bar{u}_{f}$ is the equivalent material displacement at failure (see Eq. (25)). $G_{f}$ is the failure energy. $\sigma_{y_{0}}(\bar{\varepsilon}, \bar{\varepsilon}, T)$ is the yield stress at the damage onset. $L$ is the characteristic length of the finite element.

$u_{f}=\frac{2 \times G_{f}}{\sigma_{y_{0}}(\bar{\varepsilon}, \bar{\varepsilon}, T)}$

where $G_{f}$ is the failure energy and $\sigma_{y_{0}}(\bar{\varepsilon}, \bar{\varepsilon}, T)$ is the yield stress at the damage onset.

\subsection{VUMAT validation}

The reliability of the user-material subroutine was verified for several loading conditions. 3D numerical simulations of uniaxial tensile tests along the $\mathrm{X}$-direction were firstly set up in the FE software Abaqus ${ }^{\circledR}$. The model geometry and the boundary conditions are illustrated in Fig. 7a. Tensile velocities and initial temperatures ranged between 0.01 and 100 $\mathrm{mm} / \mathrm{s}$ and $293-1073 \mathrm{~K}$, respectively, were defined. The model discretization was carried out based on the definition of one 8node thermally coupled finite element (C3D8RT). The displacement-temperature coupling and the reduced integration scheme were assumed.

The accuracy of performed implementations in the case of ultra-high dynamic conditions was also investigated. 2D numerical simulations of the axisymmetric Taylor impact test under two strain rates $\left(200 \mathrm{~m} . \mathrm{s}^{-1}\right.$ and $\left.300 \mathrm{~m} . \mathrm{s}^{-1}\right)$ were performed. This test consisted in the modeling of the 
Fig. 7 Model geometry and boundary conditions of a the 3D tensile test and $\mathbf{b}$ the $2 \mathrm{D}$ axisymmetric impact test (a)

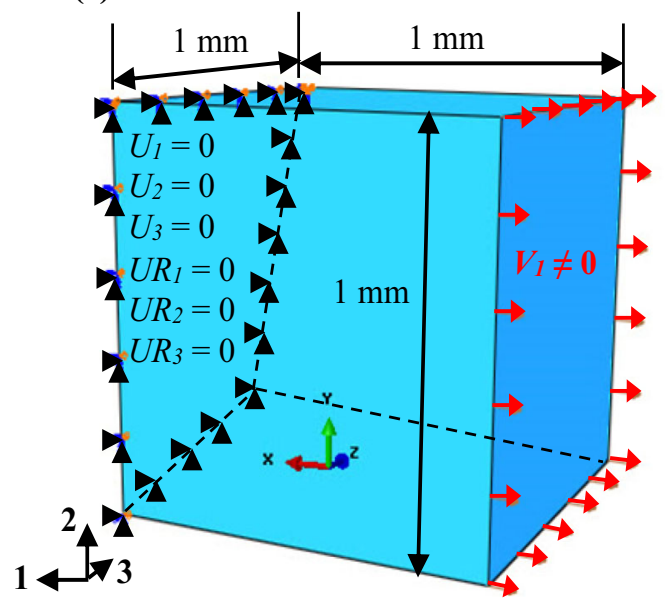

(b)

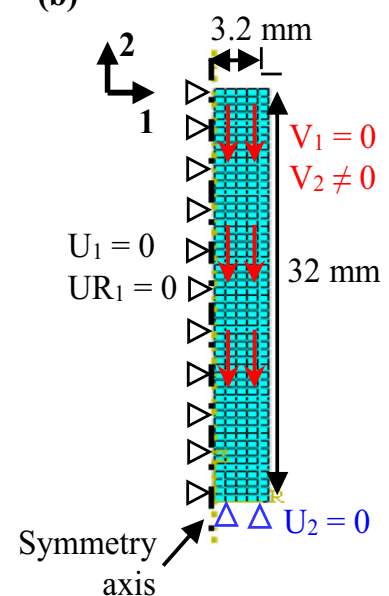

compression of a cylindrical specimen against a hardened rigid target. During the impact test, its end-face was subjected to high plastic strains. In this study, an initial temperature of $293 \mathrm{~K}$ was defined. Axial displacements of the projectile were permitted, while radial displacements were constrained (see Fig. 7b). The model discretization was done based on the definition of 270 quadrilateral axisymmetric CAX4RT mesh. The case of a reduced integration and coupled temperaturedisplacement conditions was investigated.

In the current study, no comparisons with the experimental results were set up the fact that the main purpose was to verify the reliably of performed implementations in terms of accurately reproducing the numerical results directly modeled with
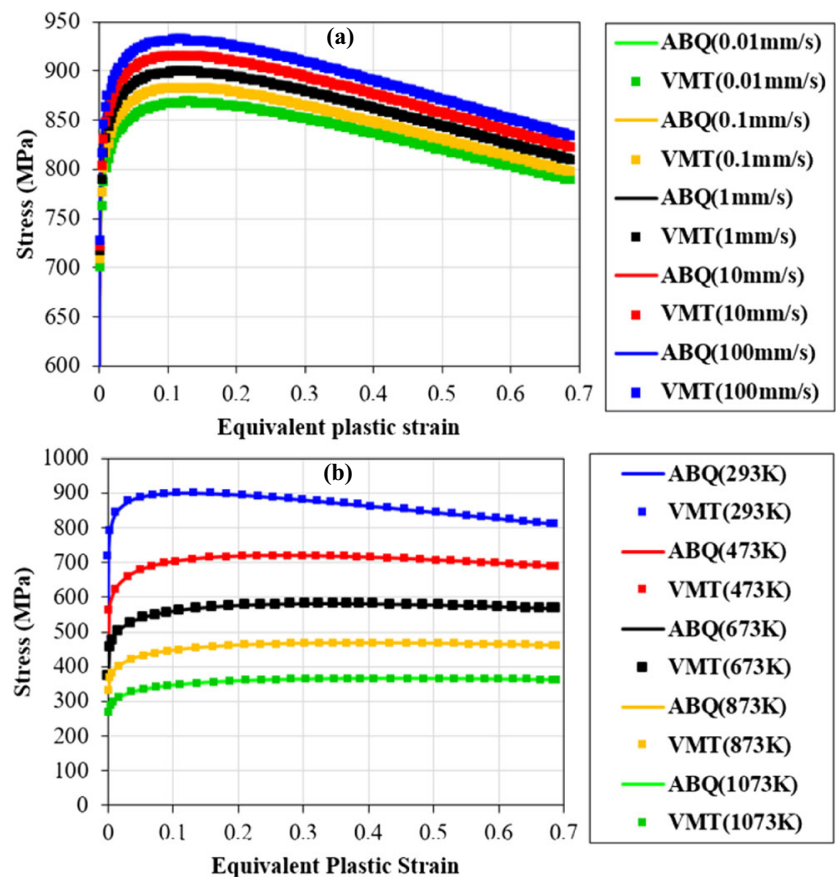

Fig. 8 Numerical stress-plastic strain curves computed with the constitutive JC model of the Abaqus ${ }^{\circledR}$ library (ABQ) or that implemented in VUMAT (VMT). a $T_{0}=293 \mathrm{~K}$ and $\mathbf{b} V=1 \mathrm{~mm} / \mathrm{s}$ the FE code Abaqus ${ }^{\circledR}$, for the same loading conditions. Therefore, the JC empirical model [18], the JC damage initiation law [35], and the failure evolution criteria (given by Eqs. (23) and (24)), which are available in the Abaqus ${ }^{\circledR}$ library, were firstly implemented in the VUMAT. The constitutive and damage coefficients regrouped in Tables 2 and 3, respectively, were defined. The same physical properties of the Ti6Al4V alloy, which were used in the FE analysis of Yaich
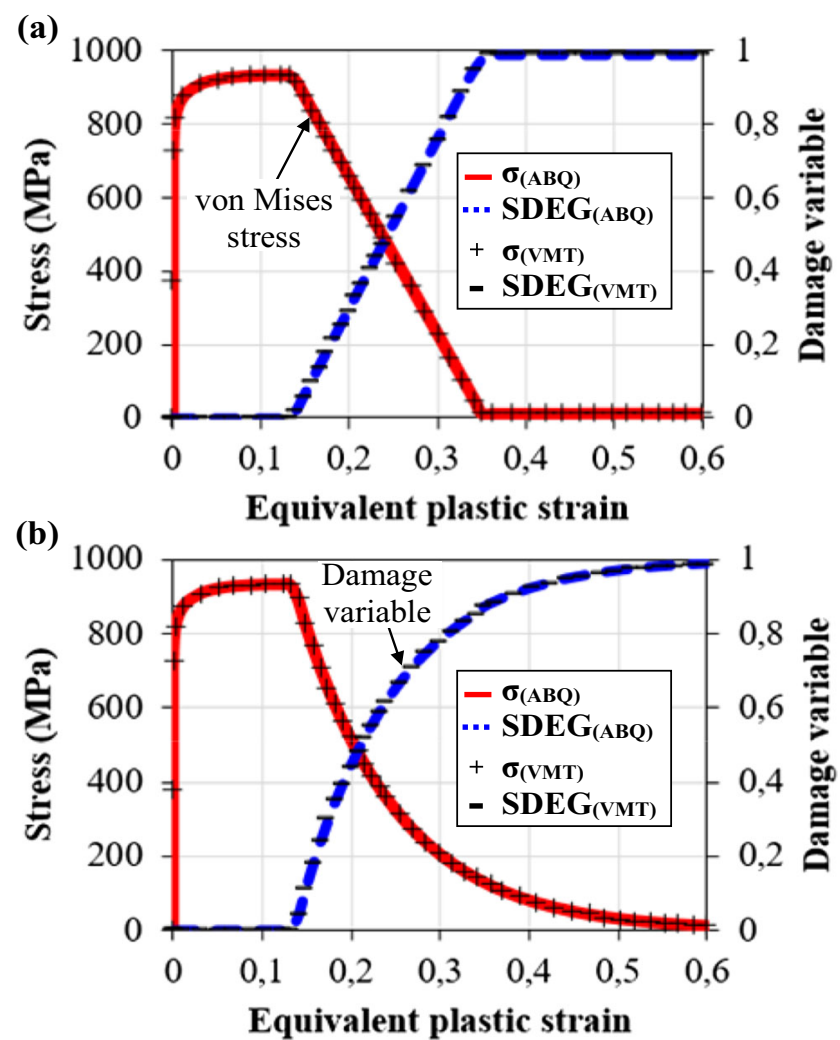

Fig. 9 Comparison of the Von Mises stress and damage variable (SDEG) predicted with Abaqus ${ }^{\circledR}$ to those obtained through the VUMAT definition $(V=100 \mathrm{~mm} / \mathrm{s})$ : Case of $\mathbf{a}$ a linear and $\mathbf{b}$ an exponential failure evolution 
et al. [22], were defined in the numerical simulations. An assumption of adiabatic conditions was made and a TaylorQuinney parameter of 0.9 was defined.

Figures 8 and 9 illustrate the numerical curves of the von Mises stresses and the damage evolution variables, respectively, which were predicted with either the direct use of constitutive/damage models implemented in the FE software Abaqus ${ }^{\circledR}$ or those defined in the programmed VUMAT. High agreements between the numerical results of uniaxial tensile tests were noted, even when the damage was initiated in the Ti6Al4V specimens. The definition of both failure evolution models resulted in a well fitting of the stress-plastic strain curves directly modeled with Abaqus ${ }^{\circledR}$ (see Fig. 9).

Figure 10 illustrates the equivalent plastic strain (PEEQ or SDV1) and the damage variable (SDEG or SDV5) computed in the deformed projectile. For both methods (with/without the VUMAT definition), a pronounced plastic strain concentration at the bottom face of the cylinder, mainly around the symmetry axis, was underlined. In addition, high correlations were noted between the numerical geometry of the deformed projectile, which was obtained either with the constitutive/ damage models available in the Abaqus ${ }^{\circledR}$ library or through those implemented in VUMAT (see Fig. 11). An extremely deformed part of the projectile was underlined resulting in the modeling of a mushroom shape in the bottom surface of the specimen. For both FE modeling methods, the same heights and radius of the deformed projectile were predicted. These pronounced correlations emphasized the accuracy of performed implementations, for quasi-static, dynamic, and ultra-high dynamic conditions.

\section{Orthogonal machining of the Ti6Al4V alloy}

\subsection{Experimental tests}

Orthogonal dry turning tests of the Ti6Al4V titanium alloy were performed on the LEADWELL LTC25iL CNC lathe. An uncoated tungsten carbide insert referenced AP40 122002-ARNO, which was fixed on the insert holder, was used. In order to reproduce the orthogonal machining configuration, the cylindrical workpiece was previously prepared
Fig. 10 Deformed projectile predicted with a, c Abaqus ${ }^{\circledR}$ and b, d through the VUMAT definition $\left(V=200 \mathrm{~m} \cdot \mathrm{s}^{-1}\right.$ and $T_{0}=$ $293 \mathrm{~K})$ : a, b equivalent plastic strain and $\mathbf{c}, \mathbf{d}$ damage evolution variable

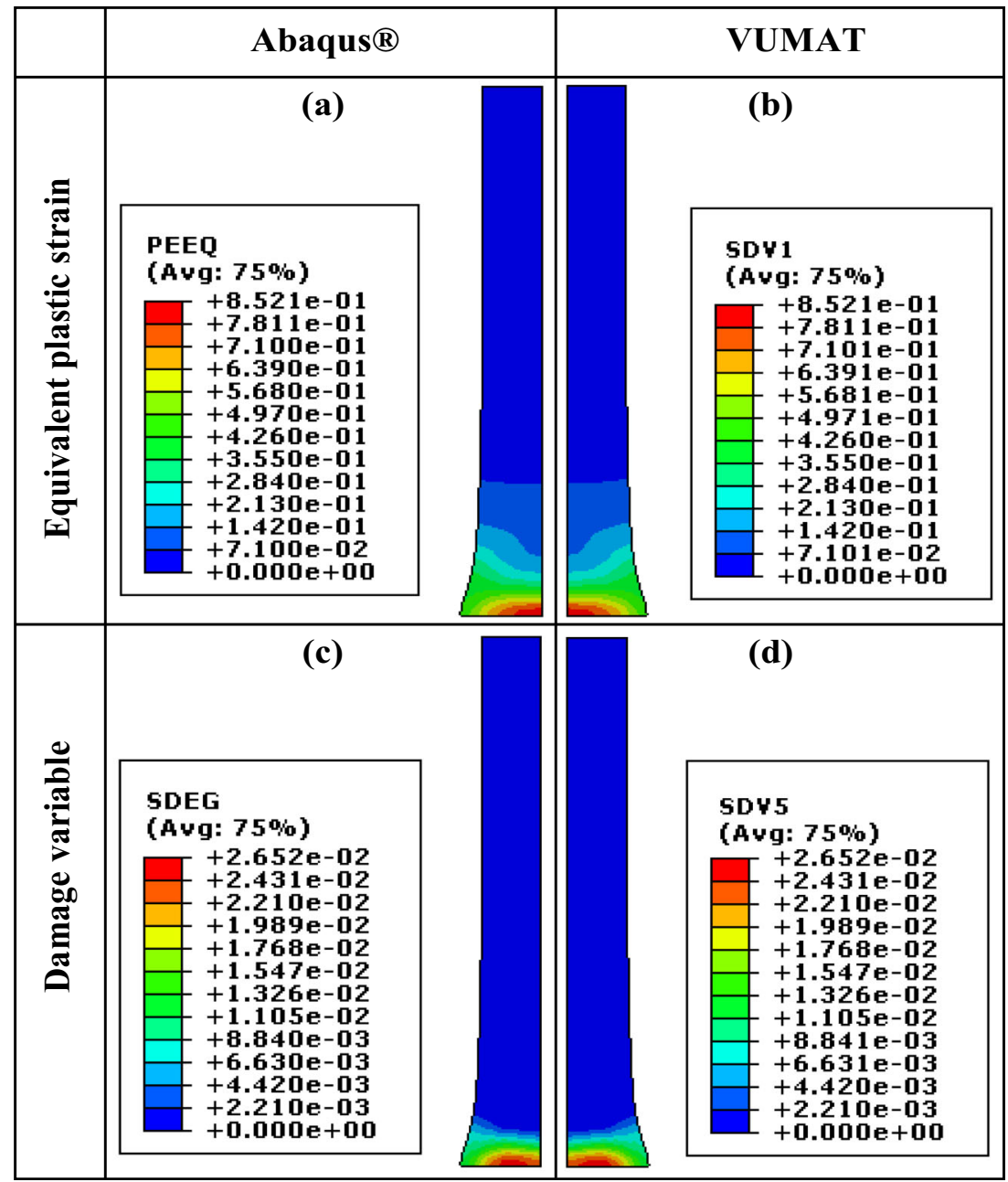




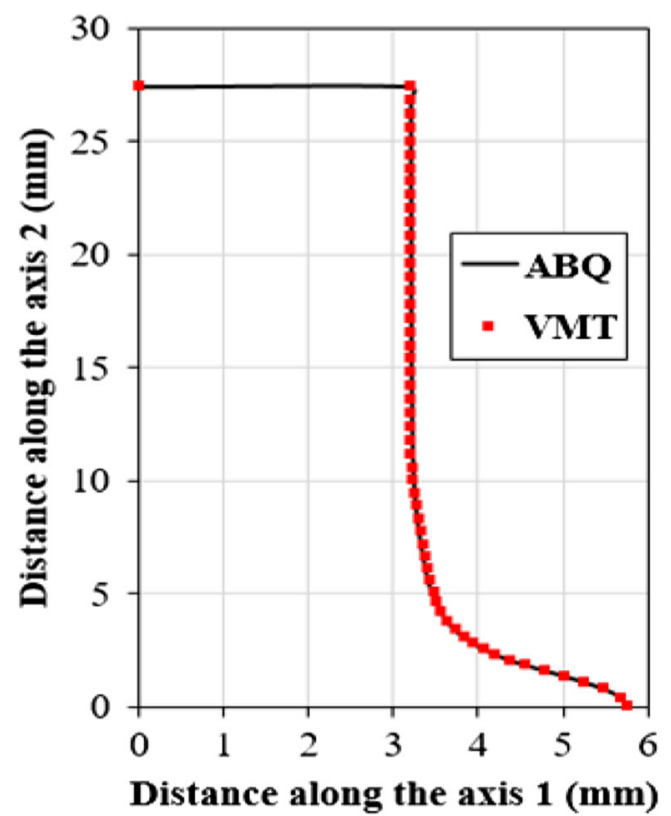

Fig. 11 Deformed projectile geometry $\left(V=300 \mathrm{~m} \cdot \mathrm{s}^{-1}\right.$ and $\left.T_{0}=293 \mathrm{~K}\right)$

with bearings of 3-mm width (Fig. 12). The cutting conditions are grouped in Table 4. Measurements of the instantaneous forces in different directions were done through the Kistler dynamometer. An optical microscope was used for the chip morphology investigation. Properties of the cutting tool geometry are summarized in Table 4.

\subsection{Numerical model}

3D numerical simulations of the orthogonal turning were carried out. An assumption of temperature-displacement coupling conditions was made. The case of explicit and Lagrangian conditions was investigated. A multi-part workpiece was defined for a better control of the mesh distortion in the heavily deformed parts, mainly in the contact interfaces

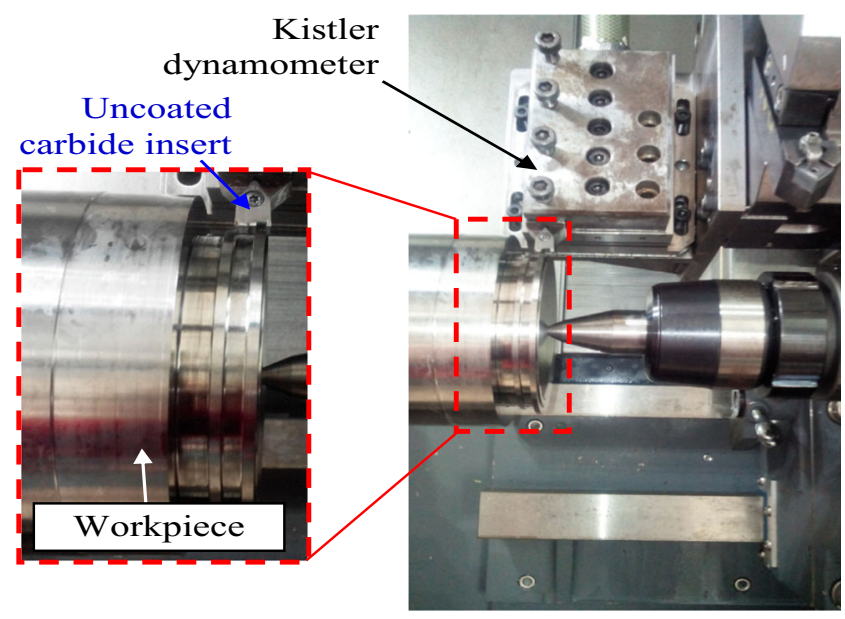

Fig. 12 Experimental machining test
Table 4 Cutting conditions, insert tool geometry, and material properties

Cutting conditions

\begin{tabular}{ll} 
Cutting speed $V_{c}(\mathrm{~m} / \mathrm{min})$ & $45-60-75$ \\
Uncut chip thickness $f(\mathrm{~mm})$ & $0.15{ }_{-} 0.22 \_0.3$ \\
Width of cut $a_{p}(\mathrm{~mm})$ & 3 \\
Tool geometry & \\
Rake angle $\gamma\left({ }^{\circ}\right)$ & 6 \\
Clearance angle $\alpha\left(^{\circ}\right)$ & 7 \\
Edge inclination angle $\lambda_{s}\left({ }^{\circ}\right)$ & 0 \\
Edge entering angle $\kappa_{r}\left({ }^{\circ}\right)$ & 90 \\
Cutting edge radius $r_{b}(\mu \mathrm{m})$ & 20 \\
Tool material properties $[37]$ & \\
Density $\rho\left(\mathrm{kg} / \mathrm{m}^{3}\right)$ & 15,000 \\
Specific heat $C_{p}(\mathrm{~J} / \mathrm{kg} / \mathrm{K})$ & 203 \\
Thermal conductivity $\lambda(\mathrm{W} / \mathrm{m} / \mathrm{K})$ & 46 \\
Thermal expansion $\alpha_{p}(\mu \mathrm{m} . \mathrm{m} / \mathrm{K})$ & $4.7 \times 10^{-6}$ \\
\hline
\end{tabular}

and the shear zones. The workpiece was conceived in three tied parts: the uncut chip zone $\left(P_{1}\right)$, the chip separation zone corresponding to the cutting tool passage zone $\left(P_{2}\right)$, and the workpiece support $\left(P_{3}\right)$. The model geometry and the boundary conditions are illustrated in Fig. 13. The cutting speed was applied to the rigid tungsten carbide tool, whereas the workpiece was fixed at its bottom side. The 8-node thermally coupled elements C3D8RT, based on the definition of the reduced integration, were used for the model discretization. A mesh refinement was applied to the tool edge radius. It was also defined to $P_{1}$ and $P_{2}$ of Fig. 13, where pronounced geometry changes were taking place. The mesh furthest from these zones was the coarsest. This assumption aimed to reduce the computing time (the $C P U$ time). The same experimental cutting conditions given by Table 4 were modeled.

In this study, the "standard" JC model [18] and the proposed one were used for the modeling of the Ti6Al4V machining. The damage initiation model [35] and the failure evolution laws (see Eqs. (23) and (24)) were defined, in the aim to allow the prediction of the material removal process, thus the chip formation and segmentation, in the case of the Lagrangian formulation definition. The Coulomb-Tresca friction model (see Eq. (26)), which has been commonly used in the literature review $[3,8,22,38]$ to model the machining process, was defined. It aimed to predict the stick-slip conditions induced in the contact interfaces. In order to model the thermomechanical coupling conditions characterizing the Ti6Al4V machining and resulting in pronounced heating of the workpiece and the cutting tool, all the energy generated by the friction work was assumed converted to a heat flow. In addition, the case of the conversion of $90 \%$ of the workpiece plastic deformation to a thermal energy was considered. 
Fig. 13 Numerical model geometry and boundary conditions

Fig. 14 Experimental chip morphologies corresponding to different cutting conditions

$$
\begin{aligned}
& \triangle U_{y}=U_{z}=0 \text { and } U R_{x}=U R_{y}=U R_{z}=0 \\
& U_{x}=U_{y}=U_{z}=0 \text { and } U R_{x}=U R_{y}=U R_{z}=0
\end{aligned}
$$
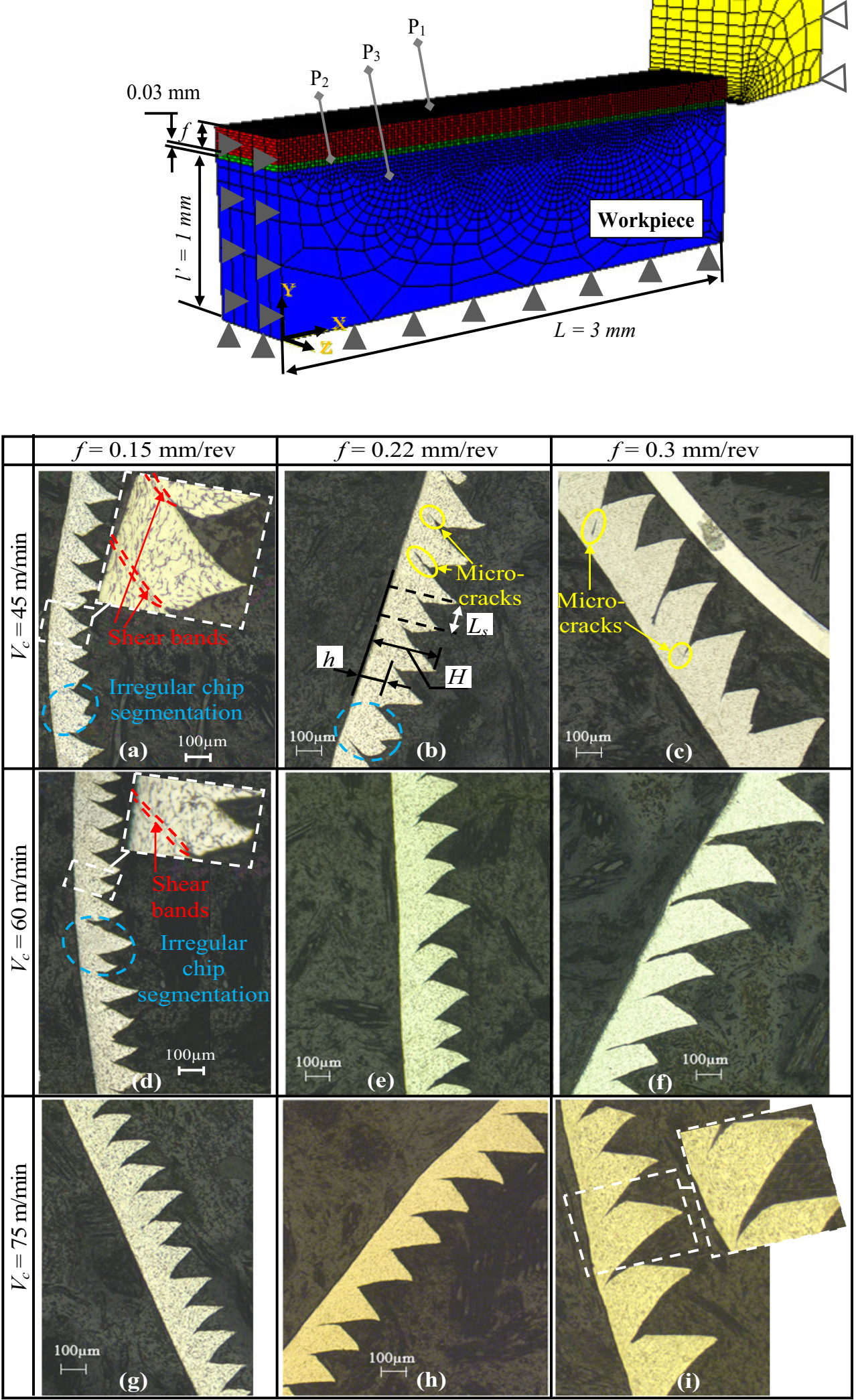
Fig. 15 Experimental average peak height (a), valley height (b), and segments width for different cutting conditions (c) (a)
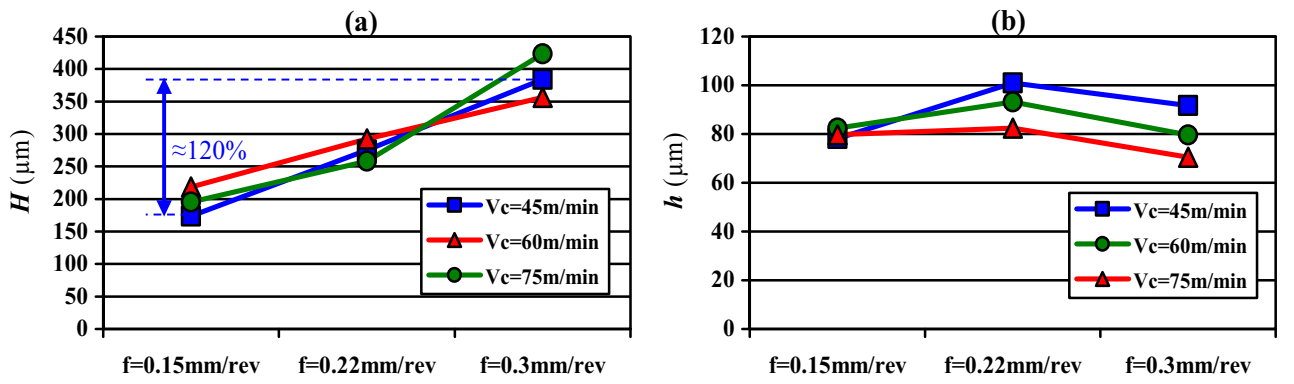

(c)

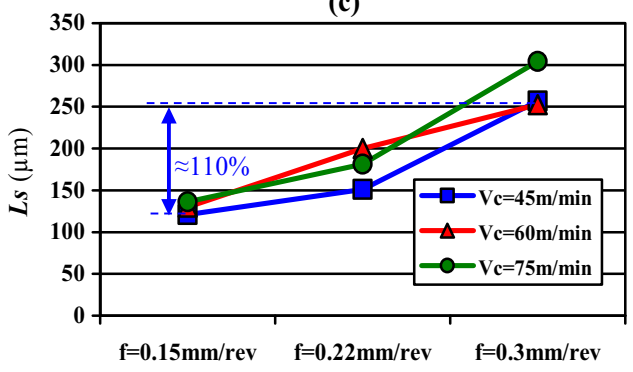

$\tau_{f}=\max \left(\mu \times \sigma_{n}, m_{\text {Tresca }} \times \frac{\sigma}{\sqrt{3}}\right)$

where $\mu$ and $m_{\text {Tresca }}$ are the Coulomb's friction coefficient and the Tresca factor, respectively. $\frac{\sigma}{\sqrt{3}}$ is the average shear stress. $\sigma_{n}$ is the normal friction stress.

\section{Experimental and numerical results of the Ti6Al4V machining}

\subsection{Chip segmentation and side burr formation}

The morphologies of experimental chips corresponding to different cutting speeds and feed rates are illustrated in Fig. 14.
For all investigated cutting conditions, the Ti6Al4V machining resulted in the formation of serrated chips. The sensitivity of the chip segmentation, the segments geometry, and the crack propagation within the formed shear bands to the machining conditions was underlined. For the lowest cutting speed and feed rate $(45 \mathrm{~m} / \mathrm{min}$ and $0.15 \mathrm{~mm} / \mathrm{rev}$, respectively), an irregular chip segmentation was underlined. However, the increase of the cutting condition gave rise to a pronounced and regular chip serration, as well as to an accentuated crack propagation. Quantitative measurements of the peak height $(H)$, the valley height $(h)$, and the segment width $\left(L_{s}\right)$ of experimental chips were made. Figure 15 illustrates a low sensitivity of the chip geometry to the cutting speeds, which was not the case of the feed rate. The $H$ and $L_{s}$ mean values were almost doubled when the feed rates was increased from 0.15 to 0.3

Fig. 16 Numerical chip morphology predicted with the JC $(\mathbf{a}-\mathbf{c})$ and the proposed rheological models for different cutting speeds $(f=0.15 \mathrm{~mm} / \mathrm{rev})$ (d-f)

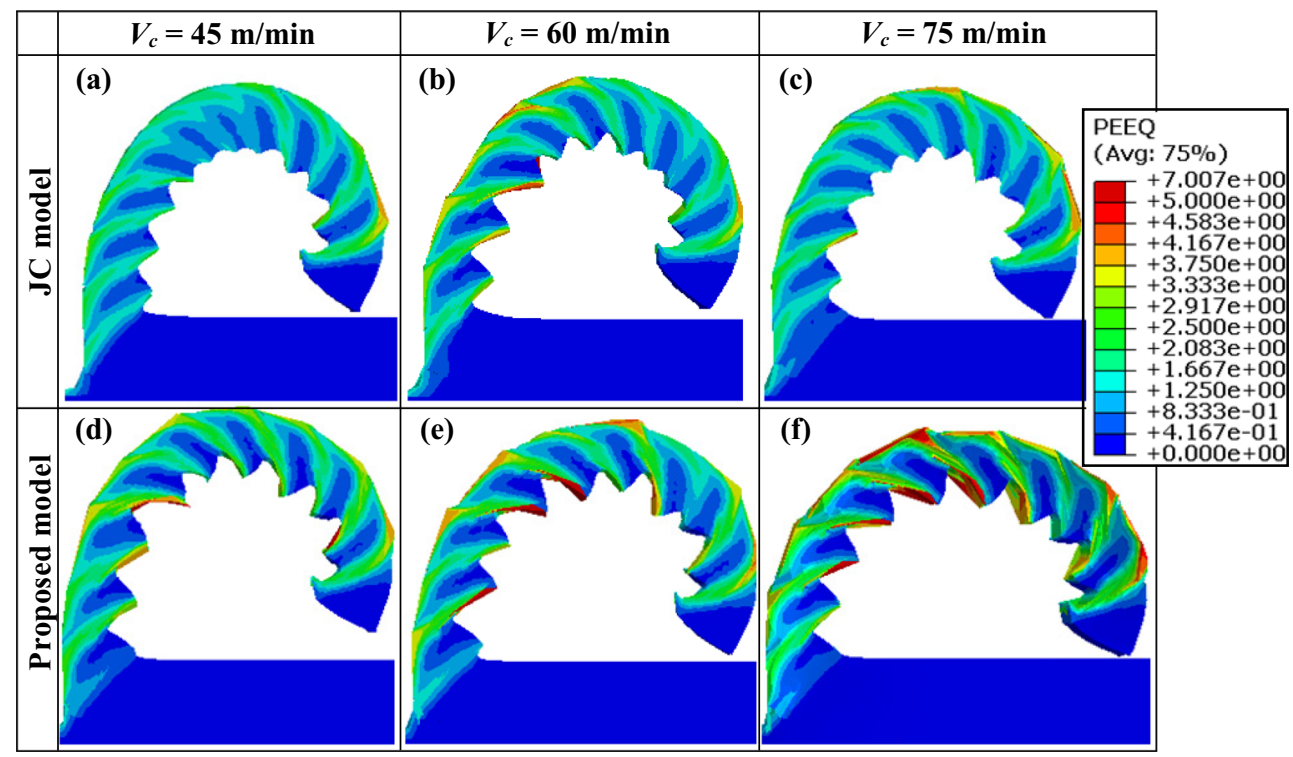


Fig. 17 Numerical chip morphology modeled with different rheological models $(f=$ $0.22 \mathrm{~mm} / \mathrm{rev})$ : case of the JC (ac) and the proposed rheological models $(\mathbf{d}-\mathbf{f})$

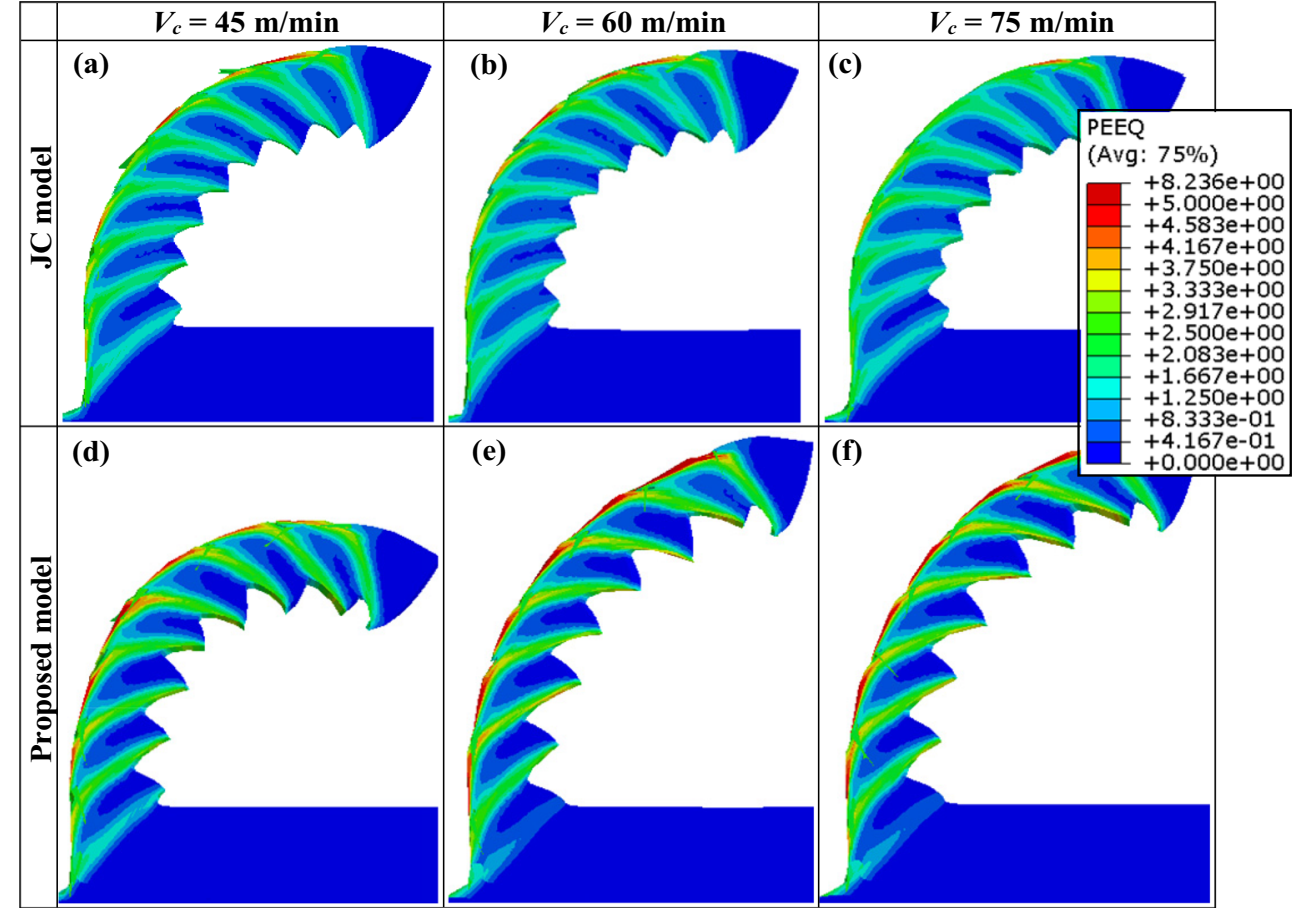

The numerical chips predicted with the JC rheological model and the proposed one were compared to the experimental ones, for the same cutting conditions. The adequacy of both models in terms of accurately predicting the machining process
Fig. 18 Numerical chip morphology corresponding to different cutting speeds and rheological models $(f=0.3 \mathrm{~mm} /$ rev). a-c JC and $\mathbf{d}-\mathbf{f}$ proposed models

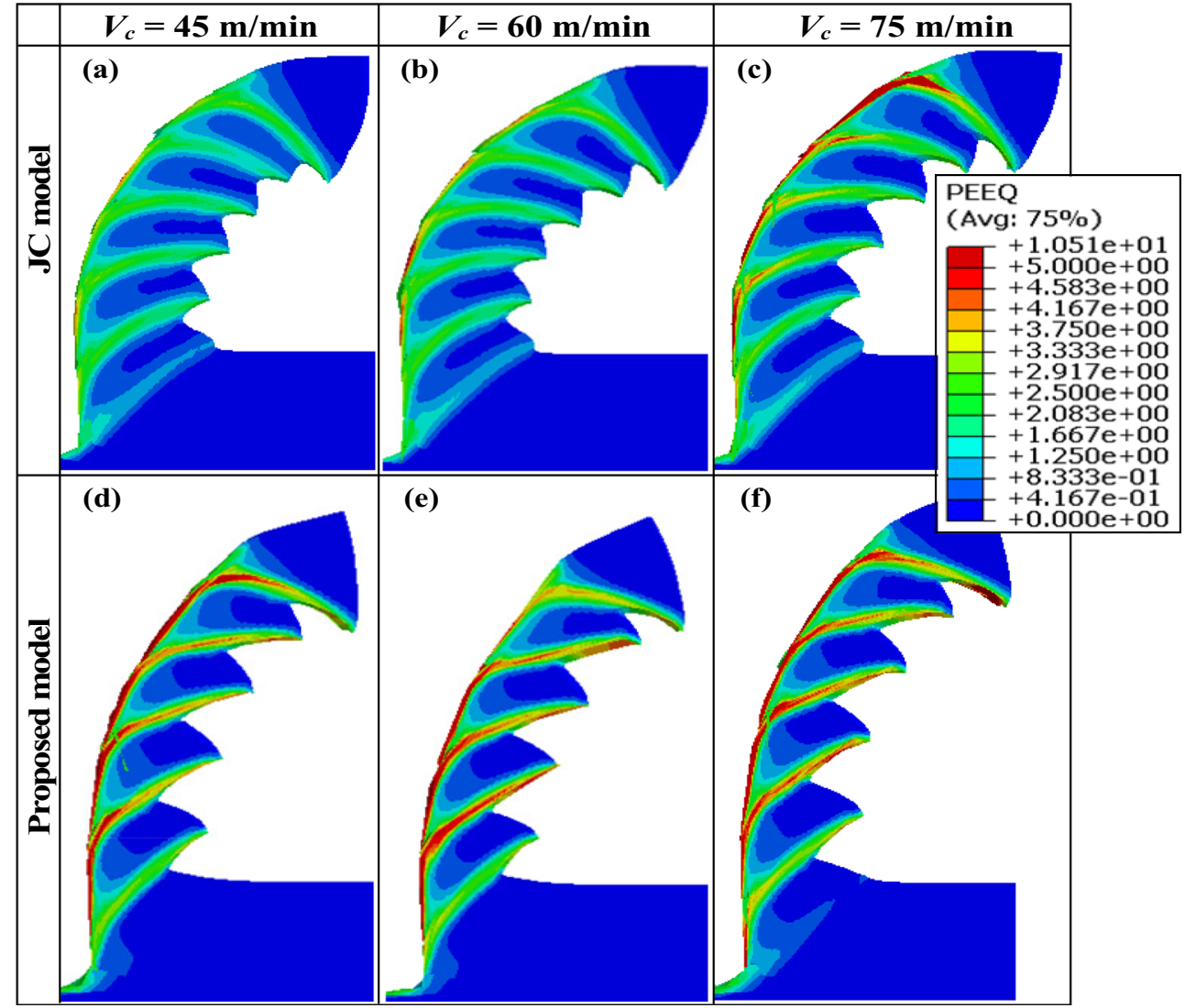


of the Ti6Al4V titanium alloy was investigated. In correlation with the experimental chip morphology, the lowest chip segmentation was modeled when a cutting speed and a feed rate of $45 \mathrm{~m} / \mathrm{min}$ and $0.15 \mathrm{~mm} / \mathrm{rev}$, respectively, were defined (see Fig. 16). For $f=0.15 \mathrm{~mm} / \mathrm{rev}$, wavy to slightly segmented chips, in a mismatch with the experimental results, were predicted with the empirical JC model, whatever the cutting speed. However, more serrated chips were simulated for the same cutting conditions, when the proposed rheological model was defined. Comparisons with the experimental chips obtained for higher feed rates $(0.22 \mathrm{~mm} / \mathrm{rev}$ and $0.3 \mathrm{~mm} / \mathrm{rev})$ underlined the inability of the JC empirical model to adequately predict the Ti6Al4V alloy behavior. Even though a slight increase of the chip serration intensity with the cutting speed was enabled with this constitutive model, Figs. 17 and 18 show the modeling of weakly segmented chips for feed rates of 0.22 $\mathrm{mm} / \mathrm{rev}$ and $0.3 \mathrm{~mm} / \mathrm{rev}$, which was in a mismatch with the experimental chip morphology. Contrariwise, an accentuation of the chip segmentation with the increase of the cutting speed and the feed rate was predicted with the proposed rheological model. For all investigated cutting conditions, numerical chips in correlation with the experimental ones were modeled with this constitutive model. Very serrated chips, with high equivalent plastic strains in the well-formed shear bands, were modeled for the highest feed rate.

Quantitative comparisons of the chip geometry were carried out to determine the reliability of the investigated phenomenological models. The peak and valley heights of numerical chips predicted with the "standard" JC model and the modified one were determined (see Fig. 19). The segmentation ratio SR (given by Eq. (27)) of experimental and numerical chips was computed and compared. It is underlined that the SR increase corresponds to a more pronounced chip segmentation. In the case of the proposed model definition, the numerical SR was generally close to the experimental ones, for the investigated cutting speeds and feed rates (see Fig. 20). Maximum errors of $15 \%$ were obtained, while mismatched chip valley and peak heights were predicted with the JC rheological model, mainly for high feed rates. In the case of $f=0.3 \mathrm{~mm} /$ rev, SR errors up to 83\% were illustrated in Fig. 20.

$$
\operatorname{SR}(\%)=100 \times\left(\frac{H-h}{H}\right)
$$

where $h$ and $H$ are the valley and the peak heights of the chip, respectively.

The comparisons of numerical chips to the experimental ones underlined the advantageous of modifications proposed to the JC rheological model. It resulted in more accurate predictions of the chip morphology and the segments geometry,
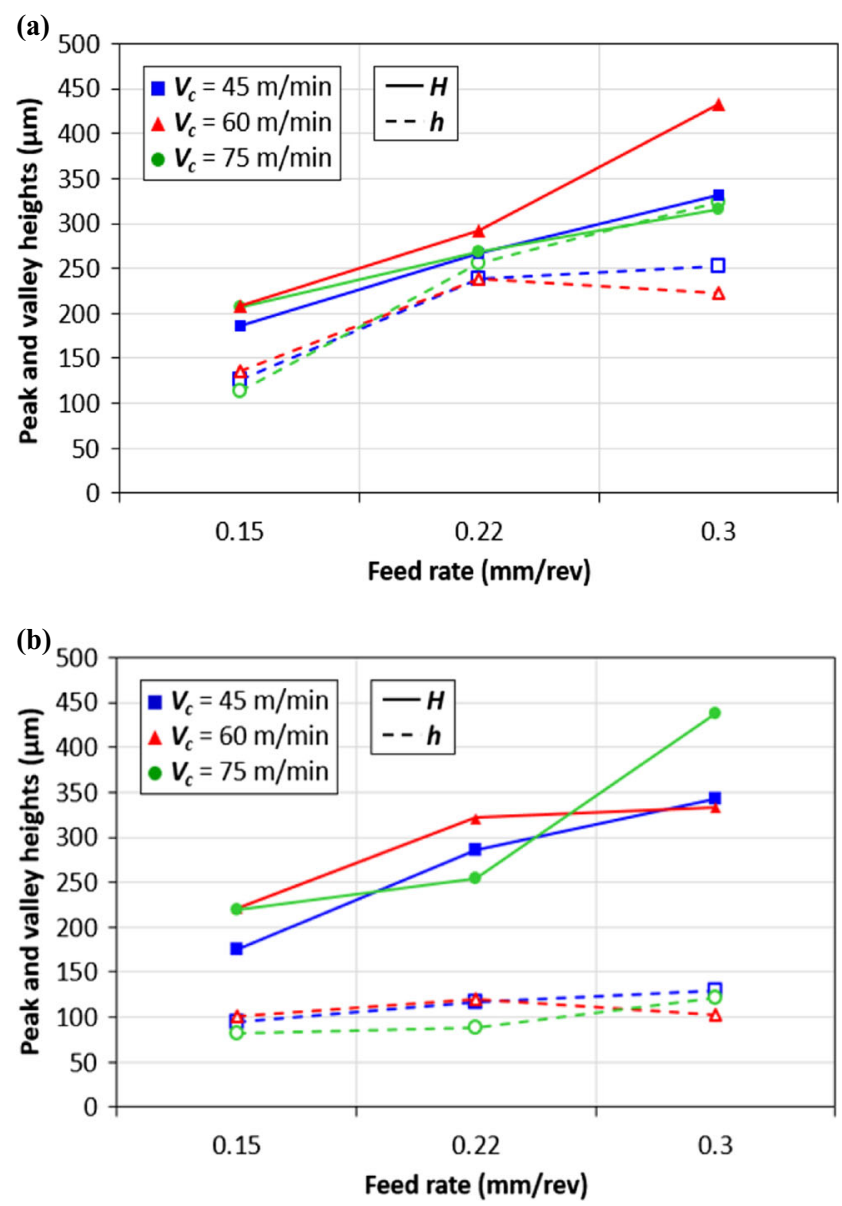

Fig. 19 Numerical peak and valley heights corresponding to different cutting conditions and constitutive models: case of $\mathbf{a} \mathrm{JC}$ and $\mathbf{b}$ proposed models

mainly in the case of high feed rates. For these cutting conditions, the efficiency of the 3D FE modeling in taking into account the influence of the material flow in the cutting direction, as well as in the width of cut direction, was underlined. The formation of side burrs in the numerical chip sides was also underlined (see Fig. 21). A low sensitivity of its average

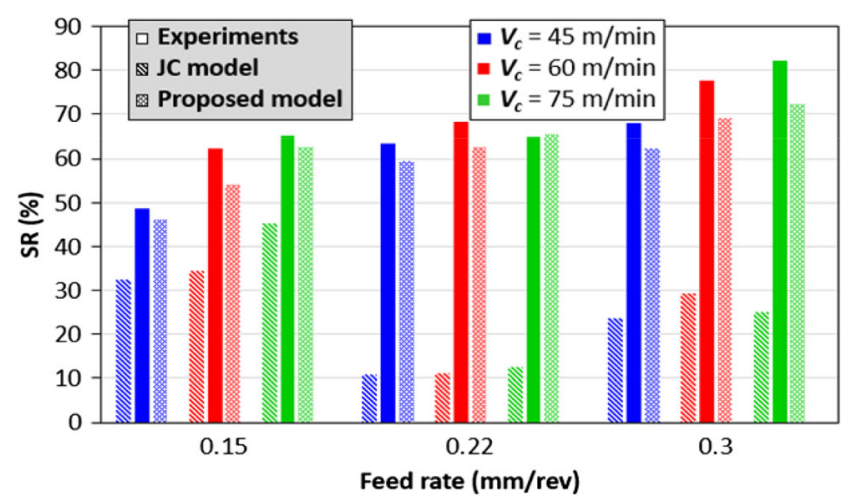

Fig. 20 Experimental and numerical segmentation ratio for different cutting conditions 
Fig. 21 Side burrs width corresponding to different cutting conditions

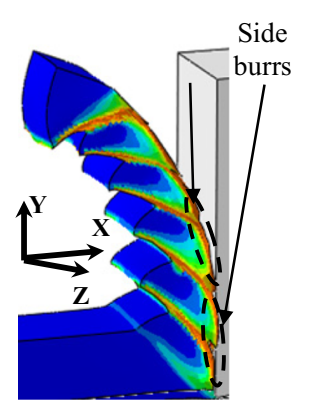

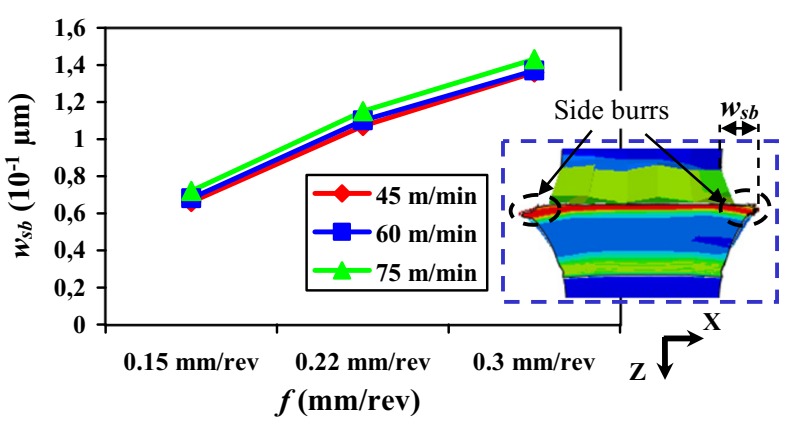

width $w_{\mathrm{sb}}$ to the cutting speed was noted. Contrariwise, the increase of the feed rate gave rise to a significant material flow in the side edges of the workpiece. For a cutting speed of 75 $\mathrm{m} / \mathrm{min}, w_{\mathrm{sb}}$ increased from 0.072 to almost $0.15 \mu \mathrm{m}$, when feed rates of $0.15 \mathrm{~mm} / \mathrm{rev}$ and $0.3 \mathrm{~mm} / \mathrm{rev}$ were modeled, respectively.

\subsubsection{Cutting forces}

The effect of the cutting conditions on the instantaneous forces applied to the cutting tool was investigated. Measurements of the cutting and feed forces were carried out once the stable regime was reached. A significant effect of the feed rate on the experimental forces was underlined (see Fig. 22). Due to the definition of the highest feed rate, the penetration of the cutting tool in the workpiece and its displacement were followed by a significant increase of the quantity of the removed material. Therefore, high cutting and feed forces were obtained during the Ti6Al4V machining. Nonetheless, Fig. 23 shows a low sensitivity of the experimental cutting forces to the cutting speed. For all studied feed rates, $F_{c}$ was slightly decreased with the $V_{c}$ increase due to the temperature rise in the contact interfaces and the shear bands. It resulted in more softening of the machined material. However, a $F_{f}$ rise with the cutting speed increase was noted (see Fig. 23b).
Comparisons of numerical cutting and feed forces to the experimental ones were set up, for all investigated cutting conditions (see Fig. 24). The low sensitivity of $F_{c}$ to the cutting speed was accurately predicted with both compared rheological models. For a feed rate of $0.15 \mathrm{~mm} / \mathrm{rev}$, numerical cutting forces were generally close to the experimental ones. Errors below $10 \%$ were computed. The pronounced sensitivity of the $F_{c}$ mean value to the feed rate was predicted with the proposed constitutive model. However, mismatched results were noted when the JC thermo-visco-plastic model was defined in the FE modeling of the Ti6Al4V orthogonal machining, mainly for the highest feed rates. Errors up to $31 \%$ were reached, while it was ranged between 0.8 and $11 \%$ in the case of the proposed model's definition to the workpiece. Even though this rheological model resulted in high correlations with the experimental chip morphology, segments geometry, and cutting forces, an underestimation of the experimental feed forces was noted for the investigated cutting conditions. Errors ranged between 19 and 30\% were computed. This disagreement was accentuated with the definition of the JC empirical model, where errors up to $41 \%$ were determined. The low reliability of both investigated constitutive models in terms of the feed forces prediction was due to the effect of residual stresses. In addition, the numerical method used by the Lagrangian formulation for the modeling of the material removal, which is based on the deletion of the totally damaged mesh, influenced the $F_{f}$ predictions.
Fig. 22 Experimental a cutting and $\mathbf{b}$ feed forces obtained for different feed rates $\left(V_{c}=45\right.$ $\mathrm{m} / \mathrm{min}$ )

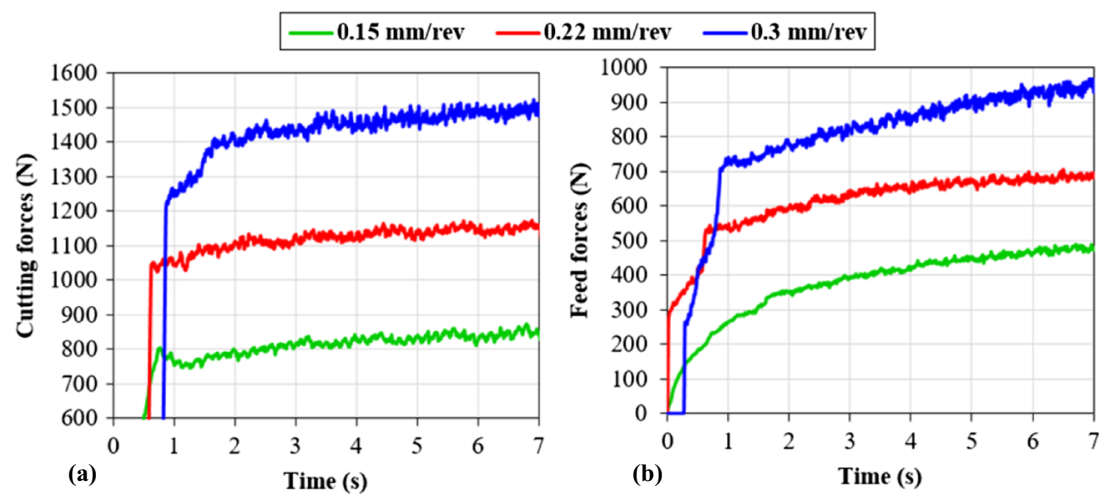


Fig. 23 Experimental a cutting and $\mathbf{b}$ feed forces corresponding to different cutting speeds $(f=$ $0.15 \mathrm{~mm} / \mathrm{rev}$ )
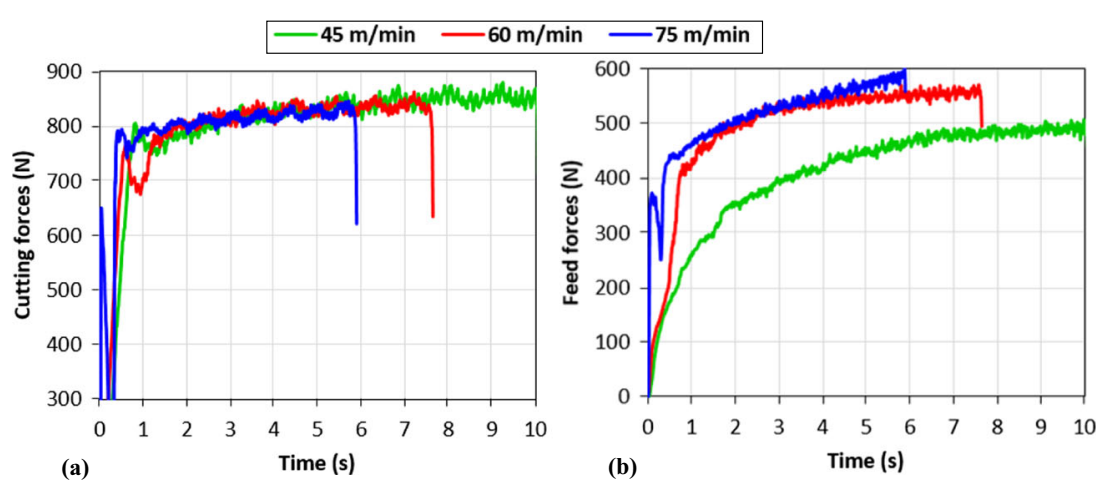

\section{Conclusion}

In this study, a new phenomenological model, based on an exponential strain sensitivity term and a generalized JC thermal softening law, was proposed. Its efficiency in terms of overcoming the weaknesses of the JC thermo-visco-plastic law, mainly summarized on its limited validity to particular strain rates and temperatures, was underlined. The identification of the proposed rheological model was carried out based on the same experimental tests used for the determination of the JC constitutive coefficients. This model ensured an interesting compromise between its identification cost and its accuracy. Its definition for the prediction of the Ti6Al4V
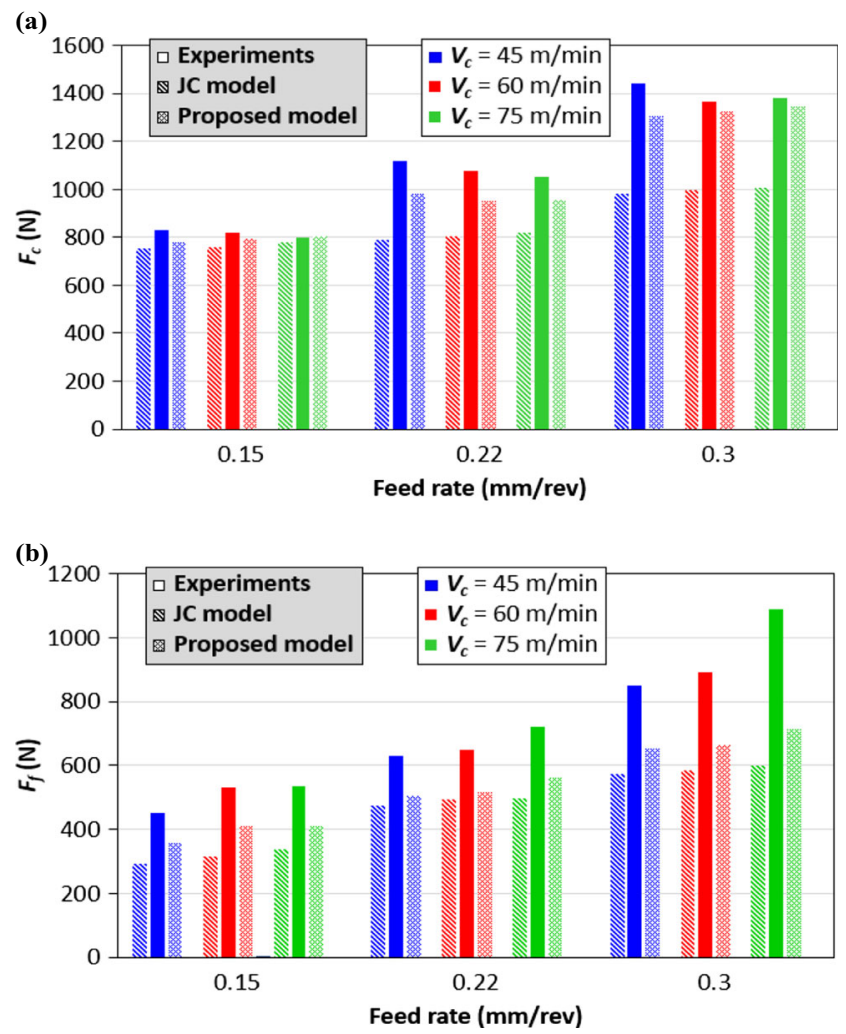

Fig. 24 Experimental and numerical mean forces corresponding to different cutting conditions: $\mathbf{a} F_{c}$ and $\mathbf{b} F_{f}$ behavior pointed out the reliability of the proposed model, for both quasi-static and dynamic conditions, as well as under wide ranges of temperatures. Its implementation in the FE code Abaqus®/Explicit through the developed subroutine VUMAT was performed. The accuracy of this subroutine was investigated based on the setting up of numerical simulations of the uniaxial tensile and axisymmetric impact tests, in which the material behavior of specimens was predicted either with the constitutive/damage models already defined in the Abaqus ${ }^{\circledR}$ library or the similar ones implemented in the VUMAT. For all investigated loading conditions, high correlations were noted underlining the reliability of performed implementations.

The experimental orthogonal cutting process of the Ti6Al4V alloy and its 3D modeling were done, for the same cutting speeds and feed rates. The efficiency of the JC rheological model and the proposed one was investigated. Comparisons were set up with the experimental results of the Ti6Al4V orthogonal machining. Despite the modeling of the same cutting conditions, different chip morphologies, segments geometries, cutting, and feed forces were predicted. The reliability of the FE analysis was increased with the definition of the proposed constitutive model. The pronounced effect of the feed rate on the chip serration, the segments geometry, and the cutting forces was suitably predicted, pointing out the accuracy of this rheological model in predicting the Ti6Al4V behavior under wide ranges of strain rates and temperatures. Contrariwise, mismatched numerical results were modeled with the JC empirical model, mainly for feed rates of $0.22 \mathrm{~mm} / \mathrm{rev}$ and $0.3 \mathrm{~mm} / \mathrm{rev}$. An underestimation of feed forces was noted for both rheological models, due to the effect of the residual stresses and the deletion of damaged FE. It was accentuated with the JC model definition.

Nonetheless, the advantages of 3D numerical simulations in terms of the modeling of the side burrs were highlighted. An increase of its width with the feed rate rise was noted. It resulted in additional thermomechanical loads, which effects on the cutting tool were neglected with the 2D FE modeling. Therefore, the limitations of 2D numerical simulations, in terms of taking into account the phenomena induced towards 
the width of cut direction, even in the case of orthogonal cutting conditions, were emphasized. In conclusion, the definition of the proposed rheological model coupled to 3D numerical simulations enabled suitable predictions of the phenomena induced in the chip thickness and width, during the Ti6Al4V machining.

Acknowledgements The authors gratefully acknowledge the financial support provided for this work by Arts et Métiers _ Campus d'Angers, France, especially the PMD team, and the National School of Engineers of Sfax, Tunisia.

Funding This study was funded by Arts et Métiers _ Campus d'Angers, France and the National School of Engineers of Sfax, Tunisia.

Data availability The data presented and analyzed in this study are available from the corresponding author on reasonable request.

Code availability The code used in this study is available from the corresponding author on a reasonable request.

\section{Declarations}

\section{Ethics approval and consent to participate Not applicable}

Consent for publication All authors consent to the publication of this research work

Conflict of interest The authors declare no competing interests.

\section{References}

1. Veiga C, Paulo Davim J, Loureiro AJR (2013) Review on machinability of titanium alloys: the process perspective. Rev Adv Mater Sci 34:148-164. https://doi.org/10.3945/jn.109.108399

2. Arrazola PJ, Garay A, Iriarte LM, Armendia M, Marya S, le Maître F (2009) Machinability of titanium alloys (Ti6Al4V and Ti555.3). J Mater Process Technol 209:2223-2230. https://doi.org/10.1016/j. jmatprotec.2008.06.020

3. Harzallah M, Pottier T, Senatore J, Mousseigne M, Germain G, Landon Y (2017) Numerical and experimental investigations of Ti-6Al-4V chip generation and thermo-mechanical couplings in orthogonal cutting. Int J Mech Sci 134:189-202. https://doi.org/ 10.1016/j.jimecsci.2017.10.017

4. Pottier T, Germain G, Calamaz M, Morel A, Coupard D (2014) Sub-millimeter measurement of finite strains at cutting tool tip vicinity. Exp Mech 54:1031-1042. https://doi.org/10.1007/s11340014-9868-0

5. Chen G, Ge J, Lu L, Liu J, Ren C (2021) Mechanism of ultra-highspeed cutting of Ti-6Al-4V alloy considering time-dependent microstructure and mechanical behaviors. Int J Adv Manuf Technol 113:193-213. https://doi.org/10.1007/s00170-021-06589-3

6. Ali MH, Ansari MNM, Khidhir BA, Mohamed B, Oshkour AA (2014) Simulation machining of titanium alloy (Ti-6Al-4V) based on the finite element modeling. J Braz Soc Mech Sci Eng 36:315324. https://doi.org/10.1007/s40430-013-0084-0

7. Arrazola PJ, Barbero O, Urresti I (2010) Influence of material parameters on serrated chip prediction in finite element modeling of chip formation process. Int J Mater Form 3:519-522. https://doi. org/10.1007/s12289-010-0821-1
8. Yaich M, Ayed Y, Bouaziz Z, Germain G (2017) Numerical analysis of constitutive coefficients effects on FE simulation of the 2D orthogonal cutting process: application to the Ti6Al4V. Int J Adv Manuf Technol 93:283-303. https://doi.org/10.1007/s00170-0168934-4

9. Biermann D, Höhne F, Sieben B, Zabel A (2010) Finite element modeling and three-dimensional simulation of the turning process incorporating the material hardness. Int J Mater Form 3:459-462. https://doi.org/10.1007/s12289-010-0806-0

10. Franchi R, Del Prete A, Umbrello D (2017) Inverse analysis procedure to determine flow stress and friction data for finite element modeling of machining. Int J Mater Form 10:685-695. https://doi. org/10.1007/s12289-016-1311-x

11. Haddag B, Atlati S, Nouari M, Znasni M (2010) Finite element formulation effect in three-dimensional modeling of a chip formation during machining. Int J Mater Form 3:527-530. https://doi.org/ 10.1007/s12289-010-0823-Z

12. Rizzuti S, Umbrello D, Filice L, Settineri L (2010) Finite element analysis of residual stresses in machining. Int J Mater Form 3:431434. https://doi.org/10.1007/s12289-010-0799-8

13. Parida AK, Maity K (2017) Effect of nose radius on forces, and process parameters in hot machining of Inconel 718 using finite element analysis. Eng Sci Technol an Int J 20:687-693. https:// doi.org/10.1016/j.jestch.2016.10.006

14. Lurdos O (2008) Lois de comportement et recristallisation dynamique: approches empirique et physique. Thesis, Ecole Nationale Supérieure des Mines de Saint-Etienne

15. Hor A (2011) Simulation physique des conditions thermomécaniques de forgeage et d'usinage - Caractérisation et modélisation de la rhéologie et de l'endommagement. Thesis, Ecole Nationale Supérieure d"Arts et Métiers Centre d'Angers

16. Ayed Y (2013) Approches expérimentales et numériques de l'usinage assisté jet d'eau haute pression: étude des mécaniques d'usure et contribution à la modélisation multi-physiques de la coupe. Thesis, Ecole Nationale Supérieure d'Arts et Métiers Centre d'Angers

17. Hor A, Morel F, Lebrun JL, Germain G (2013) Modelling, identification and application of phenomenological constitutive laws over a large strain rate and temperature range. Mech Mater 64:91-110. https://doi.org/10.1016/j.mechmat.2013.05.002

18. Johnson GR, Cook WH (1983) A constitutive model and data for metals subjected to large strains, high strain rates, and high temperatures. Proc 7th Int Symp Ballist The Hague, The Netherlands, pp $541-547$

19. Saleem W, Asad M, Zain-ul-abdein M, Ijaz H, Mabrouki T (2016) Numerical investigations of optimum turning parametersAA2024-T351 aluminum alloy. Mach Sci Technol 20:634-654. https://doi.org/10.1080/10910344.2016.1224019

20. Molinari A, Cheriguene R, Miguelez H (2012) Contact variables and thermal effects at the tool-chip interface in orthogonal cutting. Int J Solids Struct 49:3774-3796. https://doi.org/10.1016/j.ijsolstr. 2012.08.013

21. Zhang YC, Mabrouki T, Nelias D, Gong YD (2011) Chip formation in orthogonal cutting considering interface limiting shear stress and damage evolution based on fracture energy approach. Finite Elem Anal Des 47:850-863. https://doi.org/10.1016/j.finel.2011. 02.016

22. Yaich M, Ayed Y, Bouaziz Z, Germain G (2020) A 2D finite element analysis of the effect of numerical parameters on the reliability of Ti6A14V machining modeling. Mach Sci Technol 24: 509-543. https://doi.org/10.1080/10910344.2019.1698606

23. Gavrus A (2012) Constitutive equation for description of metallic materials behavior during static and dynamic loadings taking into account important gradients of plastic deformation. Key Eng Mater 504-506:697-702. https://doi.org/10.4028/www.scientific.net/ kem.504-506.697 
24. Ayed Y, Germain G, Ammar A, Furet B (2017) Thermomechanical characterization of the Ti17 titanium alloy under extreme loading conditions. Int J Adv Manuf Technol 90:1593-1603. https://doi.org/10.1007/s00170-016-9476-5

25. Laakso SVA, Niemi E (2016) Modified Johnson-Cook flow stress model with thermal softening damping for finite element modeling of cutting. Proc Inst Mech Eng Part B J Eng Manuf 230:241-253. https://doi.org/10.1177/0954405415619873

26. Liu S, Kouadri-Henni A, Gavrus A (2018) DP600 dual phase steel thermo-elasto-plastic constitutive model considering strain rate and temperature influence on FEM residual stress analysis of laser welding. J Manuf Process 35:407-419. https://doi.org/10.1016/j. jmapro.2018.07.006

27. Braham Bouchnak T (2010) Etude du comportement en sollicitations extrêmes et de l'usinabilité d'un nouvel alliage de titane aéronautique: Le Ti555-3. Thesis, Ecole Nationale Supérieure d'Arts et Métiers - Centre d'Angers

28. Ludwik P (1909) Elemente der technologischen Mechanik. Verlag Von Julius Springer, Berlin

29. Germain G, Morel A, Braham-Bouchnak T (2013) Identification of material constitutive laws representative of machining conditions for two titanium alloys: Ti6Al4V and Ti555-3. J Eng Mater Technol 135(3):1-11. https://doi.org/10.1115/1.4023674

30. Xu S, Guo YF, Ngan AHW (2013) A molecular dynamics study on the orientation, size, and dislocation confinement effects on the plastic deformation of Al nanopillars. Int J Plast 43:116-127. https://doi.org/10.1016/j.ijplas.2012.11.002

31. Balogh L, Brown DW, Mosbrucker P, Long F, Daymond MR (2012) Dislocation structure evolution induced by irradiation and plastic deformation in the $\mathrm{Zr}-2.5 \mathrm{Nb}$ nuclear structural material determined by neutron diffraction line profile analysis. Acta Mater 60: 5567-5577. https://doi.org/10.1016/j.actamat.2012.06.062
32. Yang Y, Liu B (2013) Experimental study on formation characteristics and laws of dislocation and stacking fault during cutting of titanium alloy. Adv Mater Sci Eng 1-7. https://doi.org/10.1155/ 2013/306728

33. Brett A Bednarcyk, Jacob Aboudi, Steven M Arnold (2008) The equivalence of the radial return and Mendelson methods for integrating the classical plasticity equations. Comput Mech 41:733737

34. Pipard J-M (2012) Modélisation du comportement élastoviscoplastique des aciers multiphasés pour la simulation de leur mise en forme. Thesis, Ecole Nationale Supérieure d'Arts et Métiers - Centre de Metz

35. Johnson GR, Cook WH (1985) Fracture characteristics of three metals subjected to various strains, strain rates, temperatures and pressures. Eng Fract Mech 21:31-48

36. Johnson GR, Holmquist TJ (1989) Test data and computational strength and fracture model constants for 23 materials subjected to large strains, high strain rates, and high temperatures. Los Alamos National Laboratory Report, LA-11463-MS

37. Ducobu F, Rivière-Lorphèvre E, Filippi E (2016) Material constitutive model and chip separation criterion influence on the modeling of Ti6Al4V machining with experimental validation in strictly orthogonal cutting condition. Int J Mech Sci 107:136-149. https:// doi.org/10.1016/j.ijmecsci.2016.01.008

38. Zhang XP, Shivpuri R, Srivastava AK (2014) Role of phase transformation in chip segmentation during high speed machining of dual phase titanium alloys. J Mater Process Technol 214:30483066. https://doi.org/10.1016/j.jmatprotec.2014.07.007

Publisher's note Springer Nature remains neutral with regard to jurisdictional claims in published maps and institutional affiliations. 